\title{
A dynamic bi-objective closed-loop supply chain network design considering supplier selection and remanufacturer subcontractors
}

\author{
Alireza Ghassemi ${ }^{a}$, Javad Asl-Najafi ${ }^{\mathrm{b}}$ and Saeed Yaghoubi ${ }^{\mathrm{b}}$
}

${ }^{a}$ School of Industrial and Systems Engineering, College of Engineering, University of Tehran, Iran

${ }^{b}$ School of Industrial Engineering, Iran University of Science and Technology, Iran

\begin{tabular}{l}
\hline C H R O N I C L E \\
\hline Article history: \\
Received March 2, 2017 \\
Received in revised format June \\
10,2017 \\
Accepted September 212017 \\
Available online \\
September 22 2017 \\
\hline Keywords: \\
Closed-loop supply chain \\
Supplier selection \\
Time horizon \\
Multi-objective \\
Multi-attribute decision \\
making
\end{tabular}

\section{Introduction}

Nowadays, most of the firms and organizations prefer to implement the principles of logistics management with the aim of getting goods with more appropriate price and quality. Some important purposes of logistics activities are production control, service processes, and customer needs identification. Indeed, the supply chain is a network of facilities that launch products or services to the market while it is responsible to supply the raw materials and convert them to the mid-products or final products. It also engages in distributing products to the customers. As a whole, a supply chain network may consist of suppliers, manufacturers, distributors, and customers. The topic of the traditional supply chain is about forward or direct flow of materials that mostly run from suppliers to manufacturers, manufacturers to distributors, and distributors to customers. However, in most industries, another important supply chain has been formed as reverse logistics where the materials flow in the reverse way. In other words, the products move from down-streams to the up-streams. As regards to the important role of the reverse logistics in the economic and environmental issues, it has been of great

\footnotetext{
* Corresponding author. Tel: +98 (21) 73225053

E-mail address: yaghoubi@iust.ac.ir (S. Yaghoubi)

(C) 2018 Growing Science Ltd. All rights reserved. doi: $10.5267 /$ j.uscm.2017.9.001
} 
interest in recent years (Nazari, Rafiei, \& Rabani, 2018). In order to provide more environmentallyfriendly products besides taking back the used products at their end of life, some key concepts like government legislation, social responsibility, economic and environmental concerns, and customer awareness should be taken into account (Mutha \& Pokharel, 2009). Over the past few years, the closedloop supply chain management (CLSCM) has been appeared in the literature that indicates the integration of the forward channel as a traditional mode and the reverse channel as a modern one (AslNajafi et al., 2015; Sharma, 2012). Therefore, designing an efficient CLSC is one of the most basic requirements of an organization to gain more profit (Nukala \& Gupta, 2007). On the other hand, manufacturers often outsource the corresponding processes and duties to provide sufficient confidence of regular delivering with acceptable quality and lead-time. Furthermore, it is obvious that an appropriate supplier selection plays a key role in each organization, because it reduces the costs and creates price competition. Indeed, choosing the most suitable supplier from a pool of available alternatives has now become extremely important and should be strongly taken into consideration (Karande \& Chakraborty, 2013). In today's competitive business environment, quality, time, and price are three major factors that have significant effects on developing a new level of complexity in supplier selection. Although several investigations have been performed in the area of supplier selection in open loops, this is a novel subject in CLSC networks. There are some differences between supplier selection in open loop and closed-loop networks. Note that some criteria are more important in CLSCs than open loops. As a whole, several factors such as quality, delivery, capacity, and price are considered more in supplier selection. In closed-loops, product performance criteria would be more important than open loops because the products should have some specific features like strength, durability, and lightweight to be recoverable and reusable (Amin \& Zhang, 2012).

In such a problem, criteria are in conflict with each other that result in more difficult situation for decision making. The problem can be separated into two interrelated subproblems. The first one determines that which suppliers should be selected and the second one indicates the amount of purchasing from each supplier. The flexibility of facilities and sites' capacities over the time horizon is another important point that has been deeply investigated in the current study. In this regard, we should consider future changes along with increasing knowledge about environmental friendly products to integrate economic and environmental factors. In this dynamic network design, all decisions are made over a time horizon which is finite and includes several time segments. Furthermore, it is essential to propose an approach that concentrates on other qualitative and quantitative criteria and reflects the manufacturer's policy in this field.

More importantly, as Fera et al. (2017) believe that strategic and tactical decisions are two major categories of supply chain management (SCM), we consider the both decisions in our study. The aim of this study is to find the optimal material flow, including products and parts along a CLSC with the aim of selecting appropriate suppliers. In other words, the general purpose of this paper is summarized as follows: selecting suppliers of new parts for the manufacturer, allocating orders to each supplier, determining the number of delivered products to the customers by the manufacturer, determining the number of returned products from the customers to the collection/disassembly centers, determining the amount of materials enter to the recovery or disposal centers, considering time horizon through the dynamic modeling, location of collection/disassembly centers, and optimizing the manufacturer's inventory of raw materials (or parts).

This problem will be modeled as a multi-objective programming problem that non-dominated solutions will be accepted as the best solutions for the model. The remainder of the paper is prepared as follows. In the next section, we show the relationship between our work and the previous literature. In Section 3 , a bi-objective model is proposed for a dynamic closed-loop network design. The numerical results are presented in Section 4. We finally conclude the paper in Section 5. 


\section{Literature review}

The most important task of the reverse channel is collecting and transporting the used products based on balancing between cost and environmental conditions. This function can be performed by a traditional forward chain, a separated reverse channel, or a combination of both. Design and optimization of a reverse logistics network include network structure, the number of layers, type of required facilities, and technologies. Many scholars prefer to apply the general principles to design a reverse logistics. However, some of the principles are strictly restricted by social factors and have not been qualified for the design process (Krikke et al., 2001). In a broader sense, the reverse logistics configuration should follow some specific economic and environmental perspectives such as the returned product ratio, product quality, greenness, etc. (Fleischmann et al., 2001).

Many of the papers in the area of reverse logistics network design in the related literature are based on case studies. In this regard, these models may not be general, because they have been designed for different conditions. Some authors have tried to suggest general models which can be implemented in a variety of industries. Moritz Fleischmann et al. (2001) introduced a general framework based on a location model for facilities with the focus on integrating the forward and reverse logistics. Salema et al. (2007) proposed a supply chain network design regarding constraints such as capacity, multiproduct, and uncertainty on demand and return rate. Furthermore, Zhou et al. (2008) proposed a general model of restoring products in which repairing duration and remanufacturing products are investigated in depth. In this direction, Zhou et al. (2013) analyzed three important issues including environmental factors, governmental subsidies, and return ratio alongside the maximization of the aggregate profits in a green supply chain. Singh et al. (2014) presented an economic production model with time dependent demand in a reverse channel. Note that the main reason they implemented the reverse settings is the rework process. Saffar et al. (2015) investigated a bi-objective green supply chain problem under a fuzzy programming method to be able to face with uncertain conditions. They applied Jimenez approach (Jiménez, 1996) to change the problem to the crisp model and solved it using the $\varepsilon$-constraint method.

Supplier selection is one of the fundamental issues in the supply chain literature that can affect the performance of the channels. Supplier selection is a multi-criteria decision making because criteria and techniques are two essential elements in supplier selection (Thiruchelvam \& Tookey, 2011). Ho et al. (2010) investigated 74 papers published between 2000 and 2008 and elicited the common criteria. The most used one was quality while the next criteria were delivery, price, cost, production capability, service, management, technology, financial parameters, flexibility, famousness, credibility, risk taking, safety, and external environment. Regarding this point that the criteria are in conflict with each other and improving one item makes the other one worse off, solving multi-criteria problems would find a complex nature. Thus, multi attribute decision making (MADM) methods are developed (Hwang \& Yoon, 2012). For example, Yazdani (2014) discussed on the fact that how the right suppliers can be selected when fuzzy MADM process is available. In this regard, he implemented analytical hierarchy process (AHP) (Yazdani, 2014) method to find the weights of the criteria and then ranked them using fuzzy TOPSIS method.

In the MADM methods, the best alternative can be selected among with an available number of options while they also can set priority for all of the alternatives based on mathematical programming (Ozernoy, 1987). First, the mentioned methods examine the problem, specify the related attributes and assumptions, and then give an efficient solution for each problem (Ozernoy, 1992). Since the MADM methods and especially AHP are able to simultaneously investigate the both qualitative and quantitative criteria, a lot of attention has been paid to these methods over the past few years (Calabrese et al., 2013). Regarding these points, we apply the AHP method in our study. Table 1 illustrates the most important studies of recent years in the field of supply chain network design. With the aid of Table 1, we can discover the related literature gaps to present some efficient solutions and approaches. 
Table 1

Findings of the previous literature

\begin{tabular}{|c|c|c|c|c|c|c|c|c|c|c|c|c|c|c|c|c|c|c|c|c|c|c|c|c|c|c|c|c|c|}
\hline \multirow[b]{2}{*}{ Authors } & \multicolumn{13}{|c|}{ Objective function } & \multicolumn{12}{|c|}{ Supply chain partners } & \multirow[b]{2}{*}{ 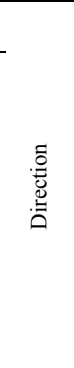 } & \multirow{2}{*}{\multicolumn{2}{|c|}{ 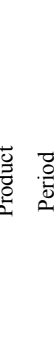 }} & \\
\hline & 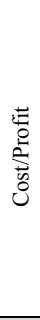 & 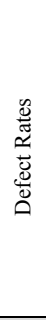 & 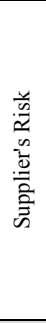 & 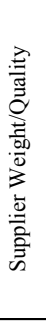 & 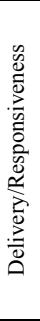 & & 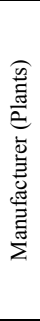 & 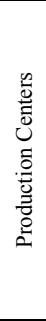 & $\begin{array}{l} \\
\mathscr{0} \\
0 \\
\overline{0} \\
\overline{0} \\
\overline{0} \\
3 \\
3\end{array}$ & 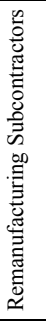 & 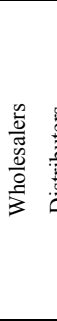 & 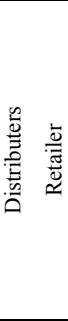 & 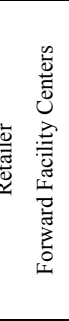 & 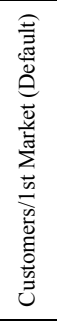 & 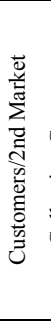 & 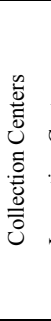 & 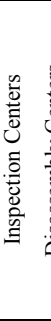 & 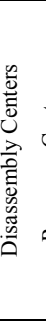 & : & 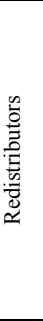 & 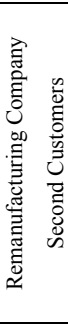 & 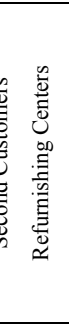 & 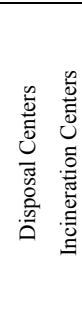 & 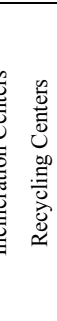 & 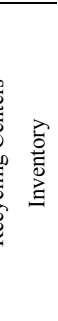 & & & & \\
\hline (Haleh \& Hamidi, 2011) & $\mathrm{P}^{*}$ & & $P$ & $P$ & & $P$ & $\mathrm{~F}$ & & & & & & & & & & & & & & & & & & & FL & $\mathrm{M}$ & M & $\mathrm{Fz}$ \\
\hline (Pishvaee et al., 2011) & $\mathrm{P}$ & & & & & & & & & & & & & $\mathrm{F}$ & $\mathrm{F}$ & $\mathrm{P}$ & $P$ & & $\mathrm{P}$ & $P$ & & & $\mathrm{~F}$ & & & $\mathrm{CL}$ & $\mathrm{S}$ & $\mathrm{S}$ & St \\
\hline (Alumur et al., 2012) & $\mathrm{P}$ & & & & & $\mathrm{F}$ & & & & $\mathrm{P}$ & & & & & F & $\mathrm{F}$ & $\mathrm{P}$ & $P$ & & & $\mathrm{P}$ & & $\mathrm{F}$ & $\mathrm{F}$ & $P$ & $\mathrm{RL}$ & M & M & $\mathrm{D}$ \\
\hline (Amin \& Zhang, 2012) & $\mathrm{P}$ & $\mathrm{P}$ & & $\mathrm{P}$ & & $P$ & $\mathrm{~F}$ & & & & & F F & & $\mathrm{F}$ & & & & $P$ & & & & $\mathrm{P}$ & $\mathrm{F}$ & & & $\mathrm{CL}$ & M & $\mathrm{S}$ & $\mathrm{D}$ \\
\hline (Nenes \& Nikolaidis, 2012) & $\mathrm{P}$ & & & & & $P$ & $\mathrm{~F}$ & & $\mathrm{~F}$ & & & & & & & & & & & & $\mathrm{~F}$ & & & & $P$ & $\mathrm{CL}$ & $\mathrm{S}$ & M & St \\
\hline (Pishvaee \& Razmi, 2012) & $\mathrm{P}$ & & & & & & & $P$ & & & & & & $\mathrm{~F}$ & & $\mathrm{P}$ & & & & & & $\mathrm{P}$ & $\mathrm{F}$ & $\mathrm{F}$ & & $\mathrm{FL}, \mathrm{RL}$ & $\mathrm{S}$ & $\mathrm{S}$ & $\mathrm{Fz}$ \\
\hline (Soleimani et al., 2013) & $\mathrm{P}$ & & & & & $P$ & $\mathrm{P}$ & & $\mathrm{P}$ & & & $\mathrm{P} \quad \mathrm{P}$ & $P$ & $\mathrm{P}$ & $\mathrm{P}$ & $\mathrm{P}$ & & $\mathrm{P}$ & & $\mathrm{P}$ & & & $P$ & & $\mathrm{P}$ & $\mathrm{CL}$ & M & M & $\mathrm{D}$ \\
\hline (Amin \& Zhang, 2013b) & $\mathrm{P}$ & $\mathrm{P}$ & & $\mathrm{P}$ & $\mathrm{P}$ & $P$ & $\mathrm{~F}$ & & & $\mathrm{P}$ & F & $\mathrm{F}$ & $F$ & $\mathrm{~F}$ & & F & & F & & & & $\mathrm{P}$ & $\mathrm{F}$ & & & $\mathrm{CL}$ & M & S & $\mathrm{Fz}$ \\
\hline (Ramezani et al., 2013) & $\mathrm{P}$ & & & $P$ & $\mathrm{P}$ & $\mathrm{F}$ & $\mathrm{P}$ & & & & & $P$ & $\mathrm{P}$ & & $\mathrm{F}$ & $P$ & & & & & & & $P$ & & & $\mathrm{CL}$ & M & $\mathrm{S}$ & $\mathrm{St}$ \\
\hline (Amin \& Zhang, 2013a) & $\mathrm{P}$ & & & & & & $\mathrm{P}$ & & & & & & & $\mathrm{P}$ & & $\mathrm{P}$ & & & & & $\mathrm{P}$ & & $\mathrm{F}$ & & & $\mathrm{CL}$ & M & $\mathrm{S}$ & $\mathrm{St}$ \\
\hline (Hatefi \& Jolai, 2014) & $\mathrm{P}$ & & & & & & & $\mathrm{P}$ & & & & $P$ & & $\mathrm{~F}$ & & $\mathrm{P}$ & & & $P$ & & & & $\mathrm{P}$ & & & $\mathrm{CL}$ & $\mathrm{S}$ & $\mathrm{S}$ & $\mathrm{St}$ \\
\hline (Moghaddam, 2015) & $\mathrm{P}$ & $\mathrm{P}$ & $P$ & & $\mathrm{P}$ & $\mathrm{P}$ & $\mathrm{P}$ & & & & & & & & & & & $\mathrm{F}$ & & & & $P$ & $\mathrm{~F}$ & & & CL & M & $\mathrm{s}$ & $\mathrm{Fz}$ \\
\hline (Ghayebloo et al., 2015) & $\mathrm{P}$ & & & & & $\mathrm{P}$ & $\mathrm{P}$ & & & & & & & $\mathrm{F}$ & & & & $P$ & & & & & & $\mathrm{~F}$ & & $\mathrm{CL}$ & M & S & D \\
\hline This Paper & $\mathrm{P}$ & & & $\mathrm{P}$ & & $\mathrm{P}$ & $\mathrm{F}$ & & & $\mathrm{P}$ & & & & $\mathrm{F}$ & & $\mathrm{P}$ & & $P$ & $\mathrm{~F}$ & & & & $\mathrm{~F}$ & & $\mathrm{P}$ & $\mathrm{CL}$ & $\mathrm{M}$ & M & D \\
\hline
\end{tabular}

\section{Model formulation}

In this section, we propose a comprehensive framework for supplier selection and supply chain network configuration that includes several steps. First, the top criteria for supplier selection are discovered and categorized. To do so, experts' opinions and experiences or previous studies can be useful. On the next step, these criteria will be reviewed and AHP gives a particular weight to each supplier based on each part. The obtained weight cooperating with another objective function and constraints will be put in a bi-objective mathematical programming to determine the material flow at each time horizon. That helps environmental protection through collecting and restoring the used items in a CLSC. The bi-objective mathematical model is solved using Augmented $\varepsilon$-Constraint (AUGMECON) (Mavrotas, 2009) and the efficient solutions are obtained.

As illustrated in Fig. 1, we assume a CLSC including a manufacturer, a recovery center, collection/disassembly centers, and disposal centers that launching products are done based on customers' demands. It is expected that under the adopted settings, some sold products may be returned to the supply chain. After collecting the returned products, the items which cannot be disassembled are transferred into the disposal centers. Other products will be disassembled and the usable parts will be sent to the recovery center to be tested and restored. In doing so, these parts are added to inventory and hold beside the fresh ones. Fresh parts are bought from external suppliers and the manufacturer produces final products by using parts. Since the collection/disassembly centers have limited capacities, we can reserve input parts to use in the next periods. In addition, the manufacturer has a limited capacity and may incur holding cost or use remanufacturing subcontractors. The manufacturer should make three major decisions: first, evaluating and selecting suppliers and allocating orders to them on different periods; second, determining the optimal number of parts and products in the supply chain flow on consecutive time segments; third, locating recovery and disposal facilities. Therefore, due to preventing sub-optimality on each mentioned steps, the manufacturer should integrate supplier selection and supply chain configuration. 


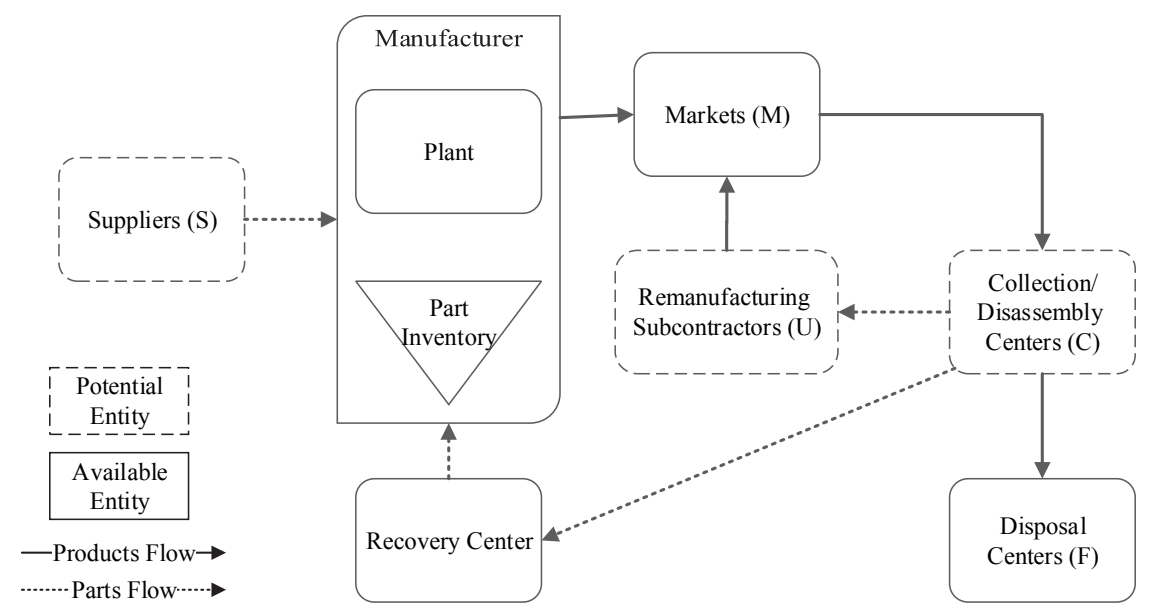

Fig. 1. Material flow in the proposed CLSC network

Here, we suggest a new framework for supplier selection which is useful in reverse logistics. The framework is categorized based on environment-related criteria (Amin \& Zhang, 2012), organizationrelated and part-related criteria, called lean and agile criteria (Abdollahi et al., 2015).

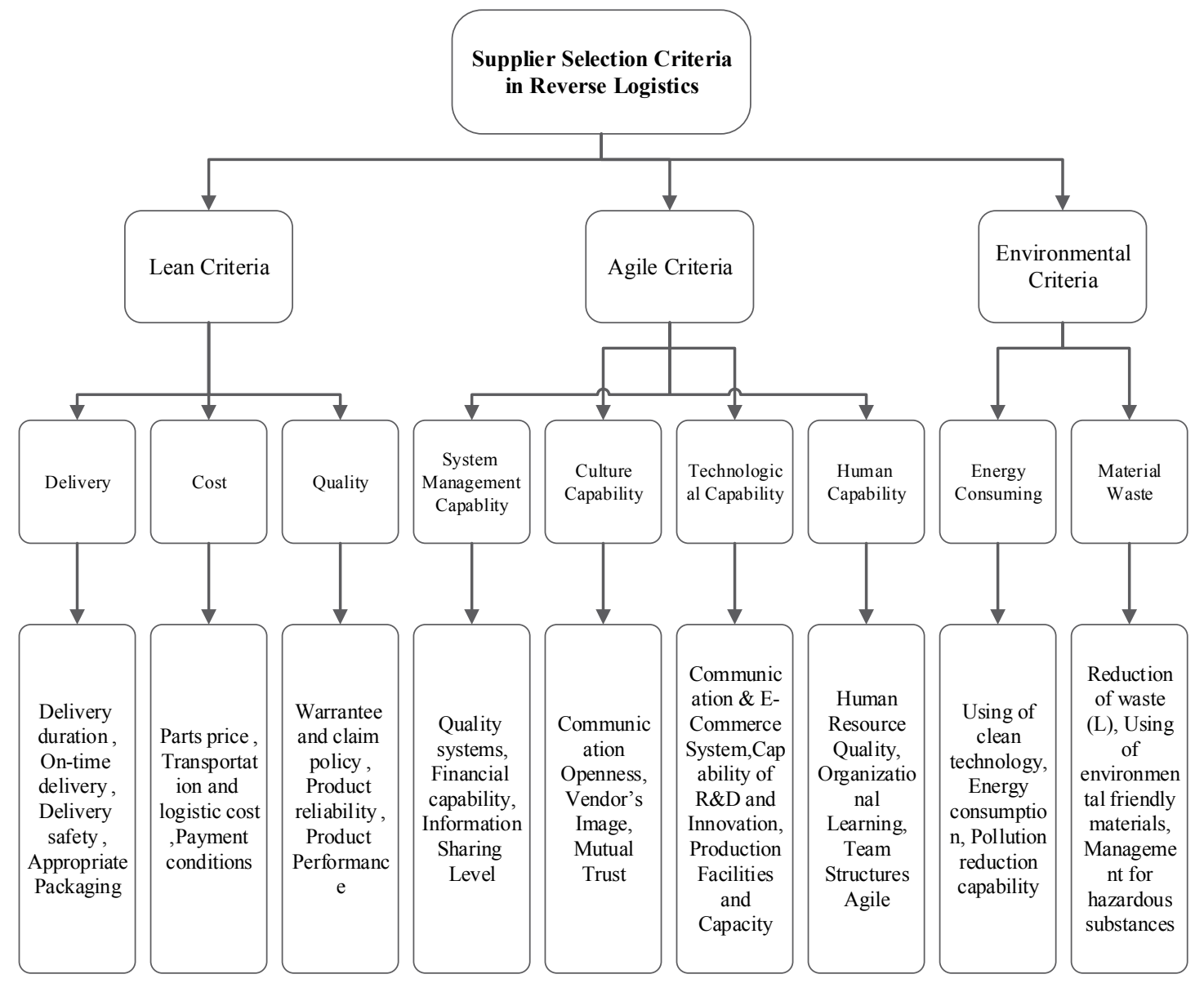

Fig. 2. Hierarchal structure for supplier selection

Fig. 2 illustrates the mentioned framework. Most studies have focused on supplier-related criteria such as delivery time, cost, financial capability, and experience without considering specific criteria relating to the processes and parts. In one of the first studies, Dickson (1966) designed a questionnaire and 
distributed it among 273 managers and procurement officers in North America. In doing so, he extracted 23 different criteria where the most important ones were quality, delivery, performance history, guarantee, claim policy, production capacity, net price, and other technical capabilities. In reverse logistics, other features like weight, durability, and strength should also be addressed. It should be noted that usable and recoverable parts can be utilized in the manufacturing process. In this process, not only parts and manufacturers should be entered, but also process-related parameters such as process capability and flexibility are essential. In addition, environment-related criteria play an important role. Pollution reduction and clean technology are some examples of green criteria in supplier selection. Interestingly, one of the reverse logistics objectives is the protection of the environment from damage. Hence, in the supplier selection process, significant weights should be considered to environmentrelated factors.

As a whole, AHP method has been most used for comparison between criteria and choosing the best alternatives. In the MADM techniques framework, AHP is one of the most used methods that has a decomposition approach so that breaks the complex problems into a structure with various objectives, criteria, and alternatives. In the first step, AHP calculates the relative importance of the variables with the aid of pairwise comparisons. Next, it selects the best option from among the all alternatives through the evaluation of the choices in the lowest stage. Indeed, the efficiency and effectiveness of the AHP method becomes more specific when the decision maker has a certain mindset. It is also noteworthy that AHP has a great potential to solve the problems that can be divided into some sub-criteria in a hierarchical path. Note that AHP can perform the prioritization mechanism by allocating a number obtained from a comparison to provide the relative importance of the criteria. Görener (2012) categorized the three basic principles of AHP method as: (1) model structure, (2) comparative judgment of the criteria and alternatives, and (3) synthesis of the priorities. To gain more details of all principles and steps of this method, we can find many studies in the literature like (Saaty, 1988).

Now, regarding Fig. 2, after comparing available suppliers by hierarchal structure, their global weights are obtained. To allocate purchasing amount from each supplier, the following mathematical model is applicable. This model is a bi-objective mathematical programming model that optimizes the defined variables. In the following, we introduce the sets, indices, decision variables, and parameters. In the next step, the mathematical model is explained in detail.

\begin{tabular}{|c|c|}
\hline \multicolumn{2}{|l|}{ Sets } \\
\hline$S$ & set of available suppliers \\
\hline $\boldsymbol{U}$ & set of remanufacturing subcontractors \\
\hline$C$ & set of available places for collection/disassembly centers \\
\hline$G$ & set of resources \\
\hline $\boldsymbol{F}$ & set of available places for disposal centers \\
\hline$M$ & set of available markets \\
\hline $\boldsymbol{R}$ & manufacturer's recovery center \\
\hline$L$ & manufacturer's plant \\
\hline $\boldsymbol{P}$ & set of products \\
\hline$Q$ & set of parts \\
\hline$T$ & set of time segments \\
\hline \multicolumn{2}{|c|}{ Parameters } \\
\hline$P R_{p}^{t}$ & price of product $\boldsymbol{p} \in \boldsymbol{P}$ at period $\boldsymbol{t} \in \boldsymbol{T}$ \\
\hline $\mathrm{CO}_{p}^{t}$ & production cost of product $\boldsymbol{p} \in \boldsymbol{P}$ at period $\boldsymbol{t} \in \boldsymbol{T}$ \\
\hline$C C_{c}^{t}$ & cost of establishing collection/disassembly center $\boldsymbol{c} \in \boldsymbol{C}$ at period $\boldsymbol{t} \in \boldsymbol{T}$ \\
\hline$O C_{c p}^{t}$ & $\begin{array}{l}\text { operation cost of product } \boldsymbol{p} \in \boldsymbol{P}(\text { part } \boldsymbol{q} \in \boldsymbol{Q}) \text { in collection/disassembly center } \boldsymbol{c} \in \boldsymbol{C} \text { (recovery center R) at } \\
\text { period } \boldsymbol{t} \in \boldsymbol{T}\end{array}$ \\
\hline$T C_{i j p}$ & transfer cost of product $\boldsymbol{p} \in \boldsymbol{P}($ part $\boldsymbol{q} \in \boldsymbol{Q})$ from site $\boldsymbol{i}$ to site $\boldsymbol{j}$ at period $\boldsymbol{t} \in \boldsymbol{T}$ \\
\hline$S C_{u q}^{t}$ & selling price of disassembled part $\boldsymbol{q} \in \boldsymbol{Q}$ to subcontractor $\boldsymbol{u} \in \boldsymbol{U}$ at period $\boldsymbol{t} \in \boldsymbol{T}$ \\
\hline
\end{tabular}


$\boldsymbol{P S}_{u p}^{t} \quad$ purchasing price of recovered product $\boldsymbol{p} \in \boldsymbol{P}$ from subcontractor $\boldsymbol{u} \in \boldsymbol{U}$ at period $\boldsymbol{t} \in \boldsymbol{T}$

$\boldsymbol{H C}_{\boldsymbol{q}} \quad$ holding cost of part $\boldsymbol{q} \in \boldsymbol{Q}$ at period $\boldsymbol{t} \in \boldsymbol{T}$

$\boldsymbol{P} \boldsymbol{C}_{s \boldsymbol{s}} \quad$ purchasing cost of part $\boldsymbol{q} \in \boldsymbol{Q}$ from supplier $\boldsymbol{S} \in \boldsymbol{S}$ at period $\boldsymbol{t} \in \boldsymbol{T}$

$\boldsymbol{D E}_{\boldsymbol{m} \boldsymbol{p}}^{\boldsymbol{t}} \quad$ demand of market $\boldsymbol{m} \in \boldsymbol{M}$ for product $\boldsymbol{p} \in \boldsymbol{P}$ at period $\boldsymbol{t} \in \boldsymbol{T}$

$\boldsymbol{W E}_{\boldsymbol{s} \boldsymbol{q}} \quad$ weight of supplier $\boldsymbol{s} \in \boldsymbol{S}$ for part $\boldsymbol{q} \in \boldsymbol{Q}$ (which is obtained from the previous step)

$\boldsymbol{N} \boldsymbol{U}_{\boldsymbol{p q}} \quad$ number of part $\boldsymbol{q} \in \boldsymbol{Q}$ that used in product $\boldsymbol{p} \in \boldsymbol{P}$

$\boldsymbol{R} \boldsymbol{U}_{\boldsymbol{c g} \boldsymbol{p}}$ resource $\boldsymbol{g} \in \boldsymbol{G}$ used at collection/disassembly center $\boldsymbol{c} \in \boldsymbol{C}$ (recovery center $\boldsymbol{R}$ ) by product $\boldsymbol{p} \in \boldsymbol{P}$ (part $\boldsymbol{q} \in \boldsymbol{Q}$ )

$\boldsymbol{R} \boldsymbol{A}_{c \boldsymbol{g}} \quad$ volume of resource $\boldsymbol{g} \in \boldsymbol{G}$ available in collection/disassembly center $\boldsymbol{c} \in \boldsymbol{C}$ (recovery center $\boldsymbol{R}$ )

$\boldsymbol{M C}_{\boldsymbol{p}}^{\boldsymbol{t}} \quad$ manufacturer's capacity for product $\boldsymbol{p} \in \boldsymbol{P}$ at period $\boldsymbol{t} \in \boldsymbol{T}$

$\boldsymbol{V}_{\boldsymbol{q}} \quad$ volume occupied by part $\boldsymbol{q} \in \boldsymbol{Q}$

IC inventory capacity at period $\boldsymbol{t} \in \boldsymbol{T}$

$\lambda_{p}^{t} \quad$ upper limit of waste rate for product $\boldsymbol{p} \in \boldsymbol{P}$ at period $\boldsymbol{t} \in \boldsymbol{T}$

$\boldsymbol{C R}_{\boldsymbol{q}}^{\boldsymbol{t}} \quad$ recovery center capacity for part $\boldsymbol{q} \in \boldsymbol{Q}$ at period $\boldsymbol{t} \in \boldsymbol{T}$

$\boldsymbol{C S}_{\boldsymbol{u q}}^{\boldsymbol{t}} \quad$ remanufacturing subcontractor capacity $\boldsymbol{u} \in \boldsymbol{U}$ for part $\boldsymbol{q} \in \boldsymbol{Q}$ at period $\boldsymbol{t} \in \boldsymbol{T}$

$\pi_{\boldsymbol{q}} \quad$ initial inventory for part $\boldsymbol{q} \in \boldsymbol{Q}$ at warehouse

Variables

$\boldsymbol{y}_{\boldsymbol{c}}^{\boldsymbol{t}} \quad$ binary variable for establishing collection/disassembly center $\boldsymbol{c} \in \boldsymbol{C}$ at period $\boldsymbol{t} \in \boldsymbol{T}$

$\boldsymbol{x}_{i j \boldsymbol{p}}^{\boldsymbol{t}} \quad$ number of product $\boldsymbol{p} \in \boldsymbol{P}$ (part $\boldsymbol{q} \in \boldsymbol{Q}$ ) transferred from $\boldsymbol{i}$ to $\boldsymbol{j}$ at period $\boldsymbol{t} \in \boldsymbol{T}$

$\boldsymbol{b}_{q}^{\boldsymbol{t}} \quad$ number of part $\boldsymbol{q} \in \boldsymbol{Q}$ holding in remanufacturer's inventory at period $\boldsymbol{t} \in \boldsymbol{T}$

Therefore, the model formulation is:

$$
\begin{aligned}
& \max Z_{1}=\sum_{t \in T} \sum_{m \in M} \sum_{p \in P}\left(P R_{p}^{t}-C O_{p}^{t}\right) x_{L m p}^{t}-\sum_{t \in T} \sum_{s \in S} \sum_{q \in Q} P C_{s q}^{t} x_{s L q}^{t}-\sum_{t \in T} \sum_{m \in M} \sum_{p \in P} T C_{L m p}^{t} x_{L m p}^{t} \\
& -\sum_{t \in T} \sum_{m \in M} \sum_{c \in C} \sum_{p \in P} T C_{m c p}^{t} x_{m c p}^{t}-\sum_{t \in T} \sum_{c \in C} \sum_{f \in F} \sum_{p \in P} T C_{c f p}^{t} x_{c f p}^{t}-\sum_{t \in T} \sum_{c \in C} \sum_{u \in U} \sum_{q \in Q} T C_{c u q}^{t} x_{c u q}^{t} \\
& -\sum_{t \in T} \sum_{c \in C} \sum_{q \in Q} T C_{c R p}^{t} x_{c R p}^{t}-\sum_{t \in T} \sum_{u \in U} \sum_{m \in M} \sum_{p \in P} T C_{u m p}^{t} x_{u m p}^{t}-\sum_{t \in T} \sum_{q \in Q} T C_{R L q}^{t} x_{R L q}^{t} \\
& -\sum_{t \in T} \sum_{s \in S} \sum_{q \in Q} T C_{s L q}^{t} x_{s L q}^{t}-\sum_{t \in T} \sum_{m \in M} \sum_{c \in C} \sum_{p \in P} O C_{c p}^{t} x_{m c p}^{t}-\sum_{t \in T} \sum_{c \in C} \sum_{q \in Q} O C_{R q}^{t} x_{c R q}^{t} \\
& -\sum_{t \in T} \sum_{m \in M} \sum_{u \in U} \sum_{p \in P} P S_{u p}^{t} x_{u m p}^{t}+\sum_{t \in T} \sum_{c \in C} \sum_{u \in U} \sum_{q \in Q} S C_{u q}^{t} x_{c u q}^{t}-\sum_{t \in T} \sum_{q \in Q} H C_{q}^{t} b_{q}^{t} \\
& -\sum_{t \in T} \sum_{c \in C} C C_{c}^{t}\left(y_{c}^{t}-y_{c}^{t-1}\right) \\
& \max Z_{2}=\sum_{t \in T} \sum_{s \in S} \sum_{q \in Q} W E_{s q} \times x_{s L q}^{t} \\
& x_{L m p}^{t}+\sum_{u \in U} x_{u m p}^{t} \geq D E_{m p}^{t} \forall t, m, p \\
& y_{c}^{t} \times B M \geq \sum_{m \in M} x_{m c p}^{t} \forall t, c, p \\
& y_{c}^{t} \times B M \geq \sum_{f \in F} x_{c f p}^{t} \forall t, c, p \\
& y_{c}^{t-1} \leq y_{c}^{t} \forall t, c \\
& b_{q}^{t}=b_{q}^{t-1}+x_{R L q}^{t}+\sum_{s \in S} x_{s L q}^{t}-\sum_{m \in M} \sum_{p \in P} N U_{p q} \times x_{L m p}^{t} \forall t, q \\
& b_{q}^{-1}=\pi_{q} \\
& \sum_{c \in C} \sum_{q \in Q} R U_{R g q} \times x_{c R q}^{t} \leq R A_{R g}^{t} \forall t, g
\end{aligned}
$$




$$
\begin{aligned}
& \sum_{m \in M} \sum_{p \in P} R U_{c g p} \times x_{m c p}^{t} \leq R A_{c g}^{t} \forall t, c, g \\
& \sum_{m \in M} x_{L m p}^{t} \leq M C_{p}^{t} \forall t, p \\
& \sum_{q \in Q} V_{q} * b_{q}^{t} \leq I C^{t} \forall t \\
& \sum_{c \in C} \sum_{f \in F} x_{c f p}^{t} \leq \lambda_{p}^{t} \forall t, p \\
& x_{c u q}^{-1}=0 \forall u, q, \mathrm{c} \\
& x_{L m p}^{t}+\sum_{u \in U} x_{u m p}^{t}=\sum_{c \in C} x_{m c p}^{t} \forall t, p, m \\
& \sum_{c \in C}^{t c u q}=\sum_{m \in M} \sum_{p \in P} N U_{p q} \times x_{u m p}^{t} \forall u, q, t \\
& \sum_{m \in M} \sum_{p \in P} N U_{p q} \times x_{m c p}^{t}=\sum_{u \in U} x_{c u q}^{t}+x_{c R q}^{t}+\sum_{f \in F} \sum_{p \in P} N U_{p q} \times x_{c f p}^{t} \forall q, t, c \\
& \sum_{c \in C} x_{c R q}^{t}=x_{R L q}^{t} \forall q, t \\
& x_{i j p}^{t} \geq 0 \quad \forall i, j, p, t \\
& y_{c}^{t} \in\{0,1\} \forall c, t \\
& b_{q}^{t} \geq 0 \quad \forall q, t \\
& \sum_{c \in C} x_{c k q}^{t}+S u r_{R q}^{t}=C R_{q}^{t} \forall q, t \\
& \epsilon \times h_{q}^{t} \leq S u r_{R q}^{t} \leq B M \times h_{q}^{t} \forall q, t \\
& x_{c u q}^{t} \leq B M \times\left(1-h_{q}^{t}\right) \forall c, u, q, t \\
& \sum_{c \in C} x_{c u q}^{t} \leq C S_{q u}^{t} \forall q, u, t \\
& \operatorname{Sur} r_{R q}^{t} \geq 0 \forall q, t \\
& h_{q}^{t} \in\{0,1\} \forall q, t
\end{aligned}
$$

The first Objective function (1) maximizes the supply chain's profit. In the first term of this function, profit yielding from production that comes from the difference between the selling price and production cost is maximized. In the second term, the cost of purchasing parts from suppliers is minimized. In the next term, minimizing transportation cost is described. In the fourth term, operation cost of the recovery and collection/disassembly centers are minimized. In the next term, outsourcing cost of the remanufacturing subcontractors is minimized. The sixth term indicates the minimization of the holding cost. Finally, in the last term, the establishing costs of the collection/disassembly centers are minimized. The global weights which obtained through AHP in the previous step will be maximized on the second Objective function (2). Obviously, we are looking for purchasing from suppliers who gained larger weights. In each period, there is a demand from the market for each product. Constraints (3) indicate the demands of each market for each product. If one product is entered to a potential collection/disassembly center, that facility must be established. This will be done by parameter $\mathrm{M}$ which is considered in Constraints (4). On the other hand, if one product (one part) exits from a potential collection/disassembly center, that must be established. This will be done by parameter $\mathrm{M}$ which is considered in Constraints (5). According to Constraints (6), establishing cost of collection/disassembly centers are high and if we establish them, they will be usable on future periods. Number of inventory parts in each period are gained from the summation of four other terms shown in Eq. (7). The first term is the number of the remaining parts from the previous periods. The second term is the number of transported parts from the recovery center. The next term is the number of parts which are purchased 
from suppliers. During the last term, decreased parts from inventory for the production process are considered. The plant has an initial inventory for each part shown in Eq. (8). Various resources are required to collect, disassemble, and recover parts and products. Furthermore, each of the resources is limited in facility sites. Eq. (9) and Eq. (10) prevent exceeding the limitation of the available resources. The manufacturer has a particular capacity for the production of each product. Eq. (11) considers an upper limit for the production process at each period. Each part occupies some spaces, which this has a constrained capacity and Eq. (12) regards that. One of the reverse logistics objectives is to help the environment by reducing waste production. If we consider a waste rate for each part at each period, we can limit transferred products to disposal centers. Eq. (13) explains this constraint. To integrate the proposed network, available facilities must have the same and rational input and output. Constraints (14)-(18) determine this rationality. According to Eq. (19), definitely, amount of the produced products are non-negative. If collection/disassembly center $\mathrm{c}$ be established at period t, the variable of Constraints (20) is one and it is zero otherwise. Based on Eq. (21), the number of inventory parts are non-negative. Constraints (22)-(27) are also taken into account, because we use the subcontractor as a recovery center capacity is completed. In these constraints, we considered $\boldsymbol{S u r}$ and $\boldsymbol{h}$ as auxiliary variables. On Constraints (22), the number of parts which are arrived to the recovery center must not exceed the capacity (if this equals to capacity, $\boldsymbol{S u r}_{\boldsymbol{R} q}{ }_{\mathrm{q}}$ will be zero and it will be positive, otherwise). If $\boldsymbol{S u r}_{\boldsymbol{R} q}{ }_{\boldsymbol{q}}$ equals to zero (completing recovery center capacity), variable $\boldsymbol{h}_{\boldsymbol{q}}^{\boldsymbol{t}}$ will be zero and if $\boldsymbol{S u r}_{\boldsymbol{R} q}^{t}$ be positive (not completing recovery center capacity), variable $\boldsymbol{h}_{q}^{\boldsymbol{t}}$ will be one. According to the Eq. (24), if $\boldsymbol{h}_{q}^{\boldsymbol{t}}$ equals to zero (completing recovery center capacity), then variable $\boldsymbol{x}_{c u q}^{t}$ will be zero.

To solve this bi-objective model, AUGMECON will be used. For the first time, this method is used by Mavrotas (2009) while it guarantees efficient solutions. The algorithm of the mentioned method has been implemented in Python programming using pulp module (Mitchell et al., 2011) and so the following results are obtained.

\section{Numerical Example}

In this section, we try to compare the suppliers' competency in each part. To do so, two suppliers are compared with each other in two separate parts. These comparisons have been done on a hierarchal structure. Explaining every comparison in different levels is out of this paper's scope and only final decision making weights for each part are explained in Appendix 1. For the beginning numerical review, the number of model sets should be specified. The manufacturer's plant is unique and it launches two kinds of products into two markets of customers. For manufacturing the product, two parts are utilized. In the first product, four first-parts and only one second-part are combined. Moreover, the second product is formed by two first-parts and five second-parts. In addition, as required, two potential collection/disassembly centers must be established. There are two disposal centers close to the collection/disassembly centers. If the capacity of the remanufacturing subcontractors becomes full, the manufacturer applies a recovery center. This model performs strategic decisions on five consecutive time segments. In the proposed model, a variety of parameters is effective. The most important one is the cost which is categorized into several items. The first category is transportation cost. The second one is operations cost. Input parts to plant, input products to disassembly centers and parts in recovery center are converted to appropriate output to be helpful for the following facility in the network. After selling unrecovered parts to the subcontractors, the recovered products must be bought from them. Thus, the third category of the cost is the purchase cost from remanufacturing subcontractors. Manufacturing inventory is the only place which material flow can stop there and it is a connector between discrete time instants. Maintaining of the parts in the inventory is costly and this is the fourth category. The fifth one is about establishing collection/disassembly centers. These small units take a large portion of cost. The sixth and the most important one is related to purchase from suppliers. One of the factors that pushes the manufacturers to collect the sold products is the high price of raw materials. On the other hand, financial items are not restricted to the costs. The manufacturer is able to consider benefit by selling products. Prices of manufactured products are described in Appendix 1 . Note that after disassembling the collecting products, we can sell parts to subcontractors for recovery 
and remanufacturing that involve another portion of incomes. The amounts of all parameters are expressed in Appendix 1.

In addition, available resources in the recovery center $\left(\boldsymbol{R} \boldsymbol{A}_{\boldsymbol{t} g}\right)$ for both resources and for all time segments is 500 units, available resources in the collection/disassembly center $\left(\boldsymbol{R} \boldsymbol{A}_{\boldsymbol{c g}}^{t}\right)$ for both resources, both centers and for all time segments are 5000 units, manufacturer capacity $(\boldsymbol{M C} \boldsymbol{p})$ for both products and for all time segments is 5000 units, inventory capacity $\left(I C^{t}\right)$ for all time segments is 900 units and upper limit of the waste rate $\left(\lambda_{p}^{t}\right)$ for both products and for all time segments is considered 60 units.

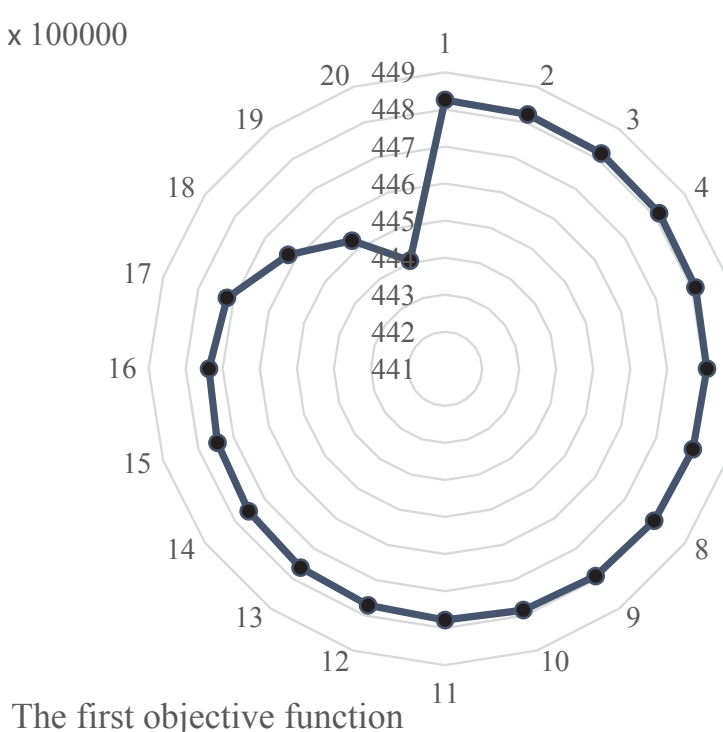

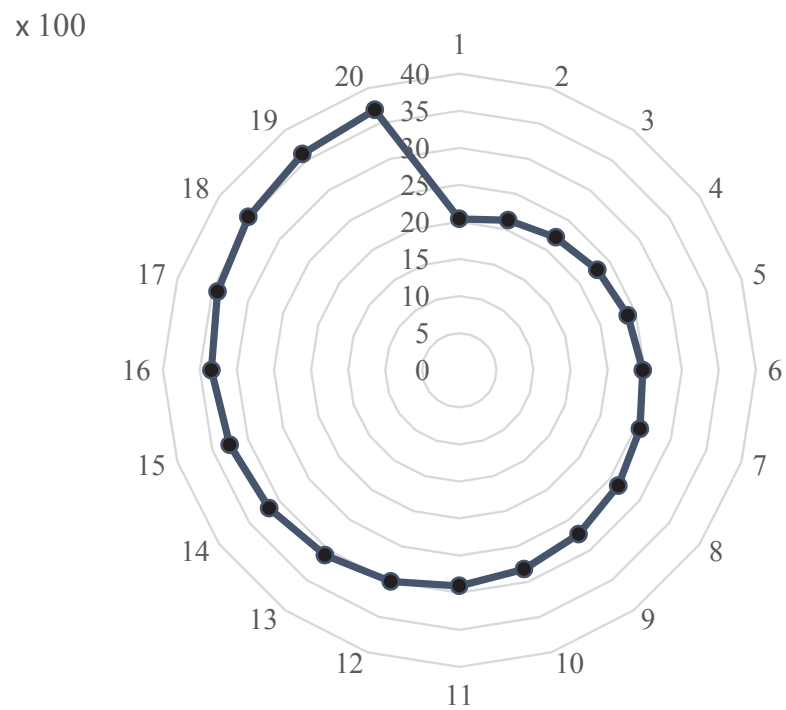

The second objective function

Fig. 3. Both objective functions for twenty efficient solutions

For generating 20 efficient solutions, this bi-objective model has been coded in Python programming language using augmented $\varepsilon$-constraint. The results of the material flow are illustrated in Appendix 2. Regarding the obtained efficient solutions, both objective functions change as depicted in Fig. 3. As can be seen in Fig. 3, achieving more utility in one of the objective functions makes the other one to get away from the best utility. Therefore, managers should do an appropriate trade-off between these two functions to obtain a favorable solution.

To analyze the impact of consecutive time segments on objective functions, we change them into less than five and solve the model for 20 efficient solutions. Fig. 4 illustrates the obtained results. As demonstrated in Fig. 4, the second objective function (right chart) is more sensitive to the time horizon changes than the first objective function (left chart). This means that the dependency of the profit on the number of decision making periods is not significant; however, supplier weights change linearly with a high slope as the periods increase. Therefore, when supplier selection problem is discussed in logistics, it is more reliable to utilize multi-period model than the single period ones. 


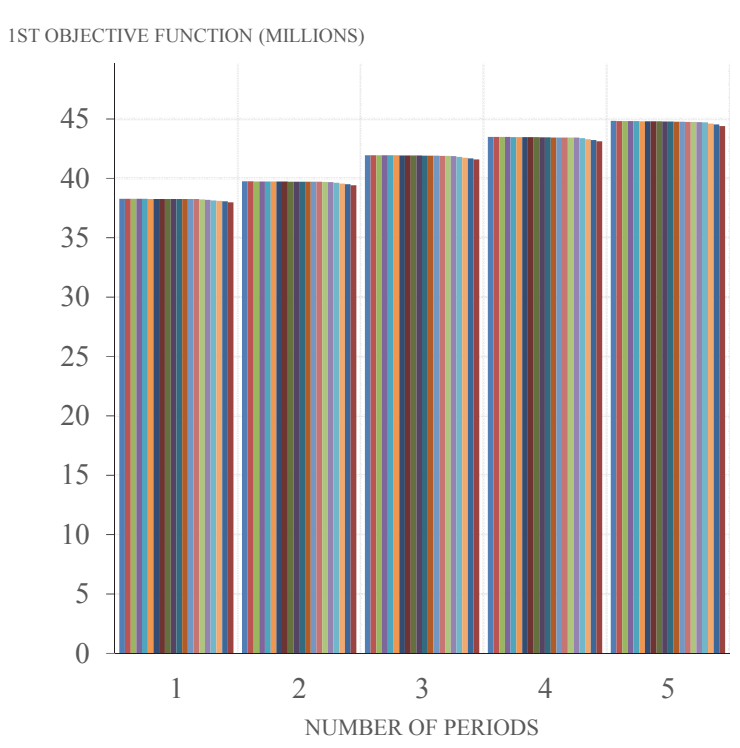

Fig.4. a. First objective functions vs. time horizon reduction

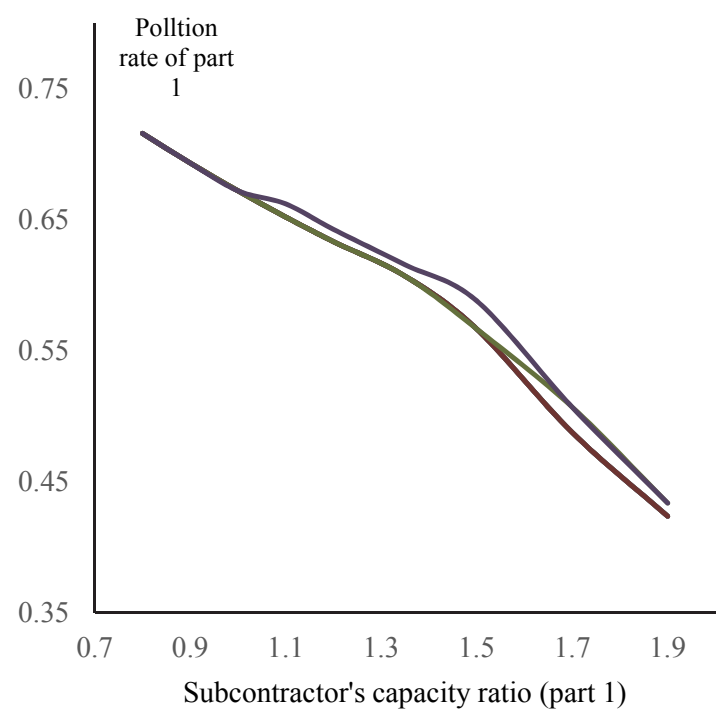

Fig. 5.a. Sensitivity of the pollution rate to the capacity of the remanufacturing subcontractors for part 1

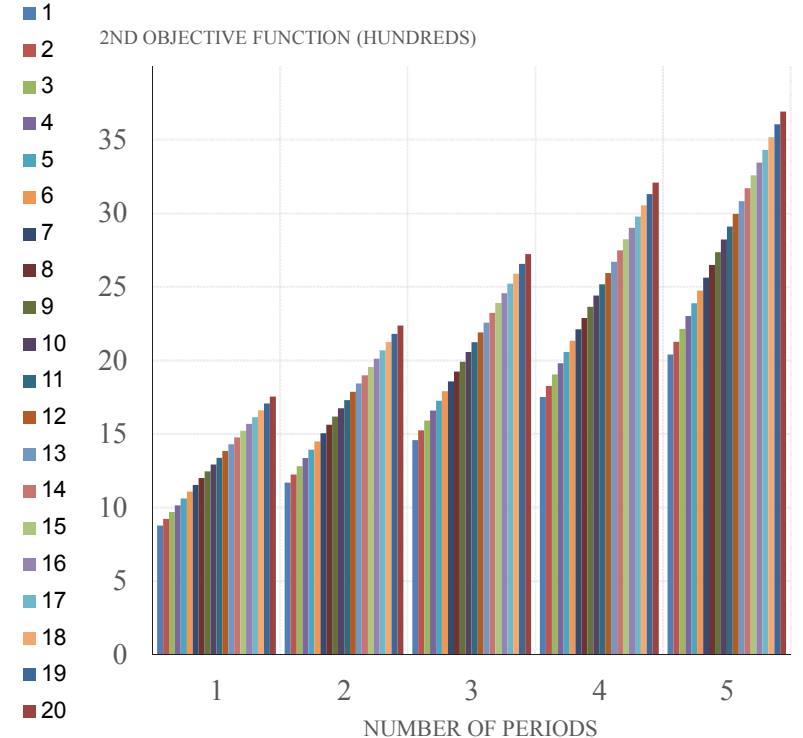

Fig.4. b. Second objective functions vs. time horizon reduction

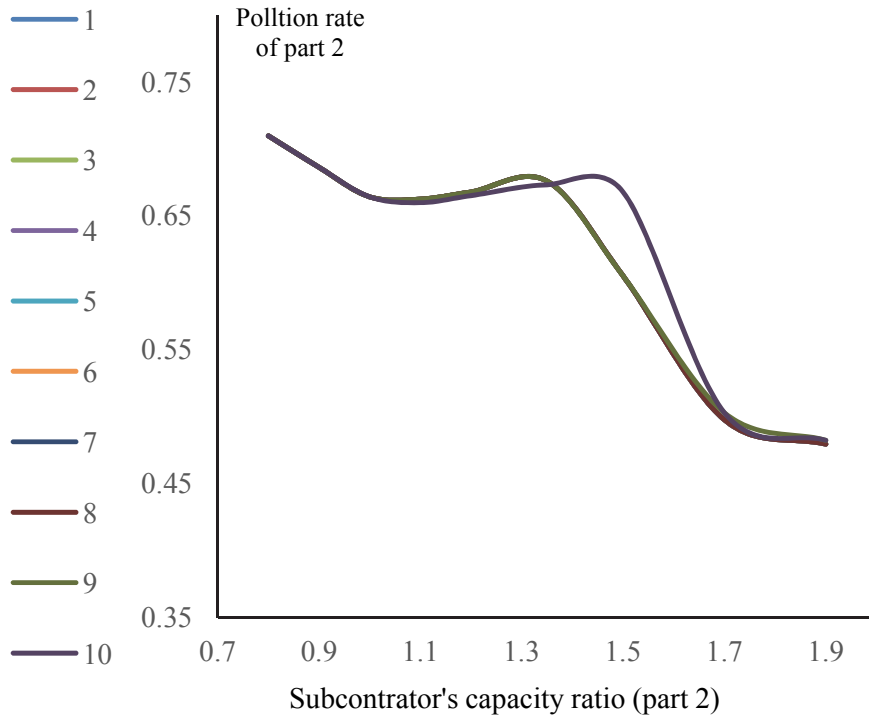

Fig. 5.b. Sensitivity of the pollution rate to the capacity of the remanufacturing subcontractors for part 2

In another analyze, we tested the sensitivity of the green network to the capacity of the remanufacturing subcontractors. First, we denote the pollution rate of each part by $\boldsymbol{\eta}_{\boldsymbol{q}}$ which can be defined as follows:

$$
\eta_{q}=\frac{\sum_{c \in C} \sum_{f \in F} \sum_{p \in P} \sum_{t \in T} x_{c f p}^{t} N U_{p q}}{\sum_{c \in C} \sum_{u \in U} \sum_{t \in T} x_{c u q}^{t}+\sum_{c \in C} \sum_{t \in T} x_{c R q}^{t}}
$$


Eq. (28) shows the ratio between parts transferred to disposal sites and the parts that are directly transferred to the manufacturer and the remanufacturers' site. Obviously, the larger $\boldsymbol{\eta}_{q}$ means the less greenness and more pollution to the environment. As can be seen in Fig. 5, we change the capacity of remanufacturing subcontractors to see the effect on the pollution rate (by implementing ten efficient solutions at each run). Although we have ten efficient solutions in Fig. 5, most of them are changing the same that each solution cannot be tracked distinctly. It is noteworthy that if the subcontractor's capacity becomes 1.5 times larger, the pollution rate of part 1 will become 0.57 in the ninth efficient solution. On the other hand, for the same solution, if the subcontractor's capacity becomes 1.5 times larger, the pollution rate of part 2 will become 0.61 . As illustrated in Fig. 5, by increasing the capacity, the pollution rate decreases. Therefore, we can improve the greenness of the CLSC network by utilizing remanufacturing subcontractors that are more powerful.

\section{Conclusion}

During the last years, due to the increasing speed and volume of communications and competitive environment development in manufacturing and servicing organizations, the importance of designing and applying an economical supply chain has received managers' attentions significantly. As a whole, supply chain network design is planned based on effectiveness of strategic factors and considering customers' requirements. One of the important decisions in the supply chain is about strategic levels. The most important topic in supply chain strategic design is the network configuration and then appropriate supplier selection. This is performed in a particular time horizon, so it is a type of strategic decision making. One important benefit of implementing supplier selection is that the low-quality parts cannot be applied in the production process. More importantly, it leads to more sustainability in the network. On the other hand, decreasing in purchase and supply costs can help the manufacturers to be able to launch more high-quality products with lower price. In order to address this issue, an exact description of the problem, detecting gaps, and designing a mathematical model have been proposed in a bi-objective mathematical modeling framework. In the first step of this model, some information is required that is obtained through an MCDM method. At the next stage, AUGMECON method is introduced to find non-dominated solutions. Finally, we verified the model by a numerical example to examine the credibility of the model in right forecasting of the system's behavior. The proposed framework and its results have enough comprehensiveness for using in future studies about reverse logistics and CLSC because it paid much attention to all effective elements in the configuration. Therefore, the manufacturers in various industries can use this model and adjust or modify it. In Iran, public and private sectors such as Ministry of Industries and Business and Department of Environment are able to utilize the proposed model and improve a green supply chain. For future extensions, we suggest special case studies along developing the model. Furthermore, considering disruption risks can be helpful to make the model more practical.

\section{References}

Abdollahi, M., Arvan, M., \& Razmi, J. (2015). An integrated approach for supplier portfolio selection: Lean or agile?. Expert Systems with Applications, 42(1), 679-690.

Alumur, S. A., Nickel, S., Saldanha-da-Gama, F., \& Verter, V. (2012). Multi-period reverse logistics network design. European Journal of Operational Research, 220(1), 67-78.

Amin, S. H., \& Zhang, G. (2012). An integrated model for closed-loop supply chain configuration and supplier selection: Multi-objective approach. Expert Systems with Applications, 39(8), 6782-6791.

Amin, S. H., \& Zhang, G. (2013a). A multi-objective facility location model for closed-loop supply chain network under uncertain demand and return. Applied Mathematical Modelling, 37(6), 41654176.

Amin, S. H., \& Zhang, G. (2013b). A three-stage model for closed-loop supply chain configuration under uncertainty. International Journal of Production Research, 51(5), 1405-1425.

Asl-Najafi, J., Zahiri, B., Bozorgi-Amiri, A., \& Taheri-Moghaddam, A. (2015). A dynamic closedloop location-inventory problem under disruption risk. Computers \& Industrial Engineering, 90, 
414-428.

Calabrese, A., Costa, R., \& Menichini, T. (2013). Using Fuzzy AHP to manage Intellectual Capital assets: An application to the ICT service industry. Expert Systems with Applications, 40(9), 37473755.

Dickson, G. W. (1966). An analysis of vendor selection and the buying process. Journal of Purchasing, 2(1), 5-17.

Fera, M., Fruggiero, F., Lambiase, A., Macchiaroli, R., \& Miranda, S. (2017). The role of uncertainty in supply chains under dynamic modeling. International Journal of Industrial Engineering Computations, 8(1), 119-140.

Fleischmann, M., Beullens, P., BLOEMHOF-RUWAARD, J. M., \& Wassenhove, L. N. (2001). The impact of product recovery on logistics network design. Production and Operations Management, 10(2), 156-173.

Ghayebloo, S., Tarokh, M. J., Venkatadri, U., \& Diallo, C. (2015). Developing a bi-objective model of the closed-loop supply chain network with green supplier selection and disassembly of products: the impact of parts reliability and product greenness on the recovery network. Journal of Manufacturing Systems, 36, 76-86.

Görener, A. (2012). Comparing AHP and ANP: an application of strategic decisions making in a manufacturing company. International Journal of Business and Social Science, 3(11).

Haleh, H., \& Hamidi, A. (2011). A fuzzy MCDM model for allocating orders to suppliers in a supply chain under uncertainty over a multi-period time horizon. Expert Systems with Applications, 38(8), 9076-9083.

Hatefi, S. M., \& Jolai, F. (2014). Robust and reliable forward-reverse logistics network design under demand uncertainty and facility disruptions. Applied Mathematical Modelling, 38(9), 2630-2647.

Ho, W., Xu, X., \& Dey, P. K. (2010). Multi-criteria decision making approaches for supplier evaluation and selection: A literature review. European Journal of Operational Research, 202(1), 16-24.

Hwang, C. L., \& Yoon, K. (1981). Methods for multiple attribute decision making. In Multiple attribute decision making (pp. 58-191). Springer Berlin Heidelberg.

Jiménez, M. (1996). Ranking fuzzy numbers through the comparison of its expected intervals. International Journal of Uncertainty, Fuzziness and Knowledge-Based Systems, 4(4), 379-388.

Karande, P., \& Chakraborty, S. (2013). Using MACBETH method for supplier selection in manufacturing environment. International Journal of Industrial Engineering Computations, 4(2), 259-279.

Krikke, H., Bloemhof-Ruwaard, J., \& van Wassenhove, L. N. (2001). Design principles for closed loop supply chains: Optimizing economic, logistics and environmental performance. Erasmus Research Institute of Management, Erasmus Universiteit.

Mavrotas, G. (2009). Effective implementation of the $\varepsilon$-constraint method in multi-objective mathematical programming problems. Applied Mathematics and Computation, 213(2), 455-465.

Mitchell, S., OSullivan, M., \& Dunning, I. (2011). PuLP: a linear programming toolkit for python. The University of Auckland, Auckland, New Zealand.

Moghaddam, K. S. (2015). Fuzzy multi-objective model for supplier selection and order allocation in reverse logistics systems under supply and demand uncertainty. Expert Systems with Applications, 42(15), 6237-6254.

Mutha, A., \& Pokharel, S. (2009). Strategic network design for reverse logistics and remanufacturing using new and old product modules. Computers \& Industrial Engineering, 56(1), 334-346.

Gooran, A., Rafiei, H., \& Rabani, M. (2018). Modeling risk and uncertainty in designing reverse logistics problem. Decision Science Letters, 7(1), 13-24.

Nenes, G., \& Nikolaidis, Y. (2012). A multi-period model for managing used product returns. International Journal of Production Research, 50(5), 1360-1376.

Nukala, S., \& Gupta, S. M. (2007, May). A fuzzy mathematical programming approach for supplier selection in a closed-loop supply chain network. In Proceedings of the 2007 POMS-Dallas meeting (pp. 4-7).

Ozernoy, V. M. (1987). A framework for choosing the most appropriate discrete alternative multiple 
criteria decision-making method in decision support systems and expert systems. Toward Interactive and Intelligent Decision Support Systems, 2, 56-64.

Ozernoy, V. M. (1992). Choosing The "Best" Multiple Criterlv Decision-Making Method. INFOR: Information Systems and Operational Research, 30(2), 159-171.

Pishvaee, M. S., Rabbani, M., \& Torabi, S. A. (2011). A robust optimization approach to closed-loop supply chain network design under uncertainty. Applied Mathematical Modelling, 35(2), 637-649.

Pishvaee, M. S., \& Razmi, J. (2012). Environmental supply chain network design using multi-objective fuzzy mathematical programming. Applied Mathematical Modelling, 36(8), 3433-3446.

Ramezani, M., Bashiri, M., \& Tavakkoli-Moghaddam, R. (2013). A new multi-objective stochastic model for a forward/reverse logistic network design with responsiveness and quality level. Applied Mathematical Modelling, 37(1), 328-344.

Saaty, T. L. (1988). What is the analytic hierarchy process?. In Mathematical models for decision support (pp. 109-121). Springer, Berlin, Heidelberg.

Saffar, M. H. S. G., \& Razmi, J. (2015). A new multi objective optimization model for designing a green supply chain network under uncertainty. International Journal of Industrial Engineering Computations, 6(1), 15-32.

Salema, M. I. G., Barbosa-Povoa, A. P., \& Novais, A. Q. (2007). An optimization model for the design of a capacitated multi-product reverse logistics network with uncertainty. European Journal of Operational Research, 179(3), 1063-1077.

Sharma, S. (2012). Towards a synergy between project and supply chain management. International Journal of Industrial Engineering Computations, 3(5), 931-938.

Singh, S., Jain, S., \& Pareek, S. (2014). An economic production model for time dependent demand with rework and multiple production setups. International Journal of Industrial Engineering Computations, 5(2), 305-314.

Soleimani, H., Seyyed-Esfahani, M., \& Shirazi, M. A. (2013). Designing and planning a multi-echelon multi-period multi-product closed-loop supply chain utilizing genetic algorithm. The International Journal of Advanced Manufacturing Technology, 68(1-4), 917-931.

Thiruchelvam, S., \& Tookey, J. E. (2011). Evolving trends of supplier selection criteria and methods. International Journal of Automotive and Mechanical Engineering, 4(1), 437-454.

Yazdani, M. (2014). An integrated MCDM approach to green supplier selection. International Journal of Industrial Engineering Computations, 5(3), 443-458.

Zhou, G., Min, H., Xu, C., \& Cao, Z. (2008). Evaluating the comparative efficiency of Chinese thirdparty logistics providers using data envelopment analysis. International Journal of physical distribution \& logistics management, 38(4), 262-279.

Zhou, P., Chen, D., \& Wang, Q. (2013). Network design and operational modelling for construction green supply chain management. International Journal of Industrial Engineering Computations, 4(1), 13-28. 
Appendix 1

Data (Mathematical model parameters)

\begin{tabular}{|c|c|c|c|c|c|c|c|c|c|c|c|c|c|c|}
\hline $\boldsymbol{P} \boldsymbol{R}_{p}^{t}$ & & & & & & $C \boldsymbol{R}_{q}^{t}$ & & & & & & $N U_{p q}$ & & \\
\hline$p / t$ & 0 & 1 & 2 & 3 & 4 & $q / t$ & 0 & 1 & 2 & 3 & 4 & $p / q$ & 1 & 2 \\
\hline 1 & 15000 & 15700 & 16400 & 17200 & 17900 & 1 & 350 & 350 & 350 & 350 & 350 & 1 & 4 & 1 \\
\hline 2 & 16000 & 17000 & 18000 & 19000 & 20000 & 2 & 380 & 380 & 380 & 380 & 380 & 2 & 2 & 5 \\
\hline$C \boldsymbol{O}_{p}^{t}$ & & & & & & $T C_{\text {ump }}^{t}$ & & & & & & $W E_{s q}$ & & \\
\hline$p / t$ & 0 & 1 & 2 & 3 & 4 & $($ (u.m.p)/t & 0 & 1 & 2 & 3 & 4 & $s / q$ & 1 & 2 \\
\hline 1 & 3000 & 3200 & 3400 & 3600 & 3800 & .11 .1 & 13 & 15 & 17 & 19 & 34 & 1 & 0.54 & 0.24 \\
\hline 2 & 3800 & 4200 & 4600 & 5000 & 5400 & 1.21. & 24 & 26 & 27 & 29 & 35 & 2 & 0.46 & 0.76 \\
\hline$C C_{c} * 0.001$ & & & & & & 1.2 .1 & 14 & 15 & 17 & 18 & 37 & $\boldsymbol{R} \boldsymbol{U}_{c g p}$ & & \\
\hline$p / t$ & 0 & 1 & 2 & 2 & 4 & 1.2 .2 & 34 & 36 & 38 & 30 & 35 & $g / p$ & 1 & 2 \\
\hline 1 & 17240 & 17680 & 18570 & 19248 & 19913 & 2.1 .1 & 15 & 17 & 18 & 19 & 42 & 1 & 13 & 35 \\
\hline 2 & 17240 & 17680 & 18570 & 19248 & 19913 & 2.1 .2 & 36 & 38 & 40 & 41 & 41 & 2 & 17 & 25 \\
\hline$O C_{c p}$ & & & & & & 2.2 .1 & 17 & 19 & 21 & 22 & 43 & $\boldsymbol{R} \boldsymbol{U}_{\boldsymbol{R} g q}$ & & \\
\hline$(c . p) / t$ & 0 & 1 & 2 & 3 & 4 & 2.2 .2 & 38 & 39 & 41 & 43 & 46 & $g / q$ & 1 & 2 \\
\hline 1.1 & 831 & 853 & 875 & 908 & 930 & $T \boldsymbol{C}_{c r q}^{t}$ & & & & & & 1 & 8 & 10 \\
\hline 1.2 & 983 & 1013 & 1046 & 1072 & 1103 & $(c . q) / t$ & 0 & 1 & 2 & 3 & 4 & 2 & 12 & 7 \\
\hline 2.1 & 993 & 1020 & 1043 & 1078 & 1103 & .11 & 21 & 24 & 26 & 28 & 30 & $V_{q}$ & & \\
\hline 2.2 & 1032 & 1060 & 1095 & 1116 & 1141 & 1.2 & 24 & 26 & 28 & 30 & 32 & $q$ & 1 & 2 \\
\hline$T C_{L m p}$ & & & & & & 2.1 & 25 & 27 & 29 & 30 & 32 & & 1.8 & 2.6 \\
\hline$(m . p) / t$ & 0 & 1 & 2 & 3 & 4 & 2.2 & 26 & 27 & 29 & 32 & 33 & & & \\
\hline 1.1 & 40 & 42 & 45 & 48 & 50 & $T C_{R L q}$ & & & & & & & & \\
\hline 1.2 & 45 & 49 & 53 & 57 & 61 & $q / t$ & 0 & 1 & 2 & 3 & 4 & & & \\
\hline 2.1 & 49 & 51 & 57 & 60 & 64 & 1 & 12 & 13 & 15 & 16 & 17 & & & \\
\hline 2.2 & 54 & 58 & 63 & 67 & 71 & 2 & 12 & 14 & 16 & 18 & 20 & & & \\
\hline$T C_{m c p}^{t}$ & & & & & & $T C_{s L q}^{t}$ & & & & & & & & \\
\hline (m.c.p)/t & 0 & 1 & 2 & 3 & 4 & $(s . q) / t$ & 0 & 1 & 2 & 3 & 4 & & & \\
\hline .11 .1 & 62 & 67 & 70 & 74 & 78 & .11 & 17 & 18 & 21 & 22 & 24 & & & \\
\hline 1.21 & 63 & 67 & 72 & 76 & 80 & 1.2 & 17 & 20 & 23 & 24 & 27 & & & \\
\hline 1.2 .1 & 64 & 68 & 72 & 76 & 80 & 2.1 & 18 & 21 & 24 & 26 & 29 & & & \\
\hline 1.2 .2 & 66 & 70 & 75 & 80 & 84 & 2.2 & 19 & 21 & 22 & 23 & 24 & & & \\
\hline 2.1 .1 & 70 & 75 & 79 & 82 & 86 & $S C_{u q}$ & & & & & & & & \\
\hline 2.1 .2 & 72 & 75 & 79 & 83 & 86 & $(u . q) / t$ & 0 & 1 & 2 & 3 & 4 & & & \\
\hline 2.2 .1 & 73 & 78 & 82 & 86 & 90 & .11 & 450 & 470 & 500 & 530 & 555 & & & \\
\hline 2.2 .2 & 78 & 82 & 86 & 91 & 95 & 1.2 & 550 & 580 & 620 & 640 & 675 & & & \\
\hline$T \boldsymbol{C}_{c f p}$ & & & & & & 2.1 & 500 & 530 & 570 & 590 & 625 & & & \\
\hline$(c . f \cdot p) / t$ & 0 & 1 & 2 & 3 & 4 & 2.2 & 580 & 6100 & 680 & 690 & 740 & & & \\
\hline .11 .1 & 48 & 53 & 57 & 62 & 66 & $\boldsymbol{P} \boldsymbol{S}_{u p}^{t}$ & & & & & & & & \\
\hline 1.21. & 50 & 54 & 59 & 63 & 67 & $($ (u.p)/t & 0 & 1 & 2 & 3 & 4 & & & \\
\hline 1.2 .1 & 52 & 57 & 61 & 64 & 68 & .11 & 7500 & 7800 & 8200 & 8500 & 8850 & & & \\
\hline 1.2 .2 & 53 & 57 & 60 & 63 & 66 & 1.2 & 8000 & 8500 & 9000 & 9500 & 10000 & & & \\
\hline 2.1 .1 & 54 & 58 & 63 & 66 & 70 & 2.1 & 7900 & 8200 & 8600 & 9000 & 9350 & & & \\
\hline 2.1 .2 & 59 & 62 & 67 & 72 & 76 & 2.2 & 8600 & 9000 & 9600 & 9900 & 10400 & & & \\
\hline 2.2 .1 & 50 & 53 & 57 & 62 & 65 & $P C_{s q}^{t}$ & & & & & & & & \\
\hline 2.2 .2 & 51 & 54 & 57 & 62 & 65 & $(s . q) / t$ & 0 & 1 & 2 & 3 & 4 & & & \\
\hline$T \boldsymbol{C}_{c u q}^{t}$ & & & & & & .11 & 500 & 520 & 540 & 560 & 580 & & & \\
\hline$($ c.u.q) $/ t$ & 0 & 1 & 2 & 3 & 4 & 1.2 & 600 & 630 & 650 & 680 & 705 & & & \\
\hline .11 .1 & 13 & 15 & 17 & 19 & 21 & 2.1 & 540 & 570 & 600 & 620 & 650 & & & \\
\hline 1.21 & 24 & 26 & 27 & 29 & 30 & 2.2 & 620 & 660 & 700 & 720 & 760 & & & \\
\hline 1.2 .1 & 14 & 15 & 17 & 18 & 19 & $\boldsymbol{D} \boldsymbol{E}_{m p}^{t}$ & & & & & & & & \\
\hline 1.2 .2 & 34 & 36 & 38 & 30 & 32 & $(m \cdot p) / t$ & 0 & 1 & 2 & 3 & 4 & & & \\
\hline 2.1 .1 & 15 & 17 & 18 & 19 & 20 & .11 & 70 & 80 & 90 & 100 & 110 & & & \\
\hline 2.1 .2 & 36 & 38 & 40 & 41 & 43 & 1.2 & 55 & 64 & 73 & 80 & 89 & & & \\
\hline 2.2 .1 & 17 & 19 & 21 & 22 & 24 & 2.1 & 41 & 47 & 53 & 59 & 65 & & & \\
\hline 2.2 .2 & 38 & 39 & 41 & 43 & 44 & 2.2 & 61 & 67 & 72 & 76 & 81 & & & \\
\hline$C S_{u q}^{t}$ & & & & & & $H C_{q}$ & & & & & & & & \\
\hline$(u . q) / t$ & 0 & 1 & 2 & 3 & 4 & $q / t$ & 0 & 1 & 2 & 3 & 4 & & & \\
\hline .11 & 511 & 518 & 524 & 531 & 538 & 1 & 25 & 29 & 33 & 38 & 42 & & & \\
\hline 1.2 & 447 & 452 & 259 & 465 & 471 & 2 & 28 & 34 & 40 & 47 & 53 & & & \\
\hline 2.1 & 258 & 264 & 270 & 277 & 282 & & & & & & & & & \\
\hline 2.2 & 372 & 378 & 385 & 392 & 398 & & & & & & & & & \\
\hline
\end{tabular}


Appendix 2

Results (Efficient solutions set for material flow variables)

\begin{tabular}{|c|c|c|c|c|c|c|c|c|c|c|c|c|c|c|c|c|c|c|c|c|c|c|}
\hline \multicolumn{3}{|c|}{$\boldsymbol{x}_{s L q}^{t}{ }^{*}$} & \multicolumn{20}{|c|}{ Efficient solutions set } \\
\hline$S$ & $q$ & $t$ & 1 & 2 & 3 & 4 & 5 & 6 & 7 & 8 & 9 & 10 & 11 & 12 & 13 & 14 & 15 & 16 & 17 & 18 & 19 & 20 \\
\hline 1 & 1 & 0 & 614 & 614 & 614 & 614 & 614 & 614 & 614 & 614 & 614 & 614 & 614 & 614 & 614 & 614 & 614 & 614 & 614 & 614 & 614 & 614 \\
\hline 1 & 1 & 1 & 454 & 454 & 454 & 454 & 454 & 454 & 454 & 454 & 454 & 454 & 454 & 454 & 454 & 454 & 454 & 454 & 454 & 454 & 454 & 454 \\
\hline 1 & 1 & 2 & 452 & 452 & 452 & 452 & 452 & 452 & 452 & 452 & 452 & 452 & 452 & 452 & 452 & 452 & 452 & 452 & 452 & 452 & 452 & 452 \\
\hline 1 & 1 & 3 & 446 & 446 & 446 & 446 & 446 & 446 & 446 & 446 & 446 & 446 & 446 & 446 & 446 & 446 & 446 & 446 & 446 & 446 & 446 & 446 \\
\hline 1 & 1 & 4 & 634 & 634 & 634 & 634 & 634 & 634 & 634 & 634 & 634 & 634 & 634 & 634 & 634 & 634 & 634 & 634 & 634 & 634 & 634 & 1134 \\
\hline 1 & 2 & 0 & 1022 & 855 & 688 & 521 & 354 & 187 & 20 & 0 & 0 & 0 & 0 & 0 & 0 & 0 & 0 & 0 & 0 & 0 & 0 & 0 \\
\hline 1 & 2 & 1 & 105 & 105 & 105 & 105 & 105 & 105 & 105 & 0 & 0 & 0 & 0 & 0 & 0 & 0 & 0 & 0 & 0 & 0 & 0 & 0 \\
\hline 1 & 2 & 2 & 446 & 446 & 446 & 446 & 446 & 446 & 446 & 446 & 446 & 446 & 334 & 167 & 0 & 0 & 0 & 0 & 0 & 0 & 0 & 0 \\
\hline 1 & 2 & 3 & 431 & 431 & 431 & 431 & 431 & 431 & 431 & 389 & 222 & 55 & 0 & 0 & 0 & 0 & 0 & 0 & 0 & 0 & 0 & 0 \\
\hline 1 & 2 & 4 & 650 & 650 & 650 & 650 & 650 & 650 & 650 & 650 & 650 & 650 & 650 & 650 & 650 & 483 & 316 & 149 & 0 & 0 & 0 & 0 \\
\hline 2 & 1 & 0 & 0 & 0 & 0 & 0 & 0 & 0 & 0 & 0 & 0 & 0 & 0 & 0 & 0 & 0 & 0 & 0 & 0 & 0 & 0 & 0 \\
\hline 2 & 1 & 1 & 0 & 0 & 0 & 0 & 0 & 0 & 0 & 0 & 0 & 0 & 0 & 0 & 0 & 0 & 0 & 0 & 0 & 0 & 0 & 0 \\
\hline 2 & 1 & 2 & 0 & 0 & 0 & 0 & 0 & 0 & 0 & 0 & 0 & 0 & 0 & 0 & 0 & 0 & 0 & 0 & 0 & 0 & 0 & 0 \\
\hline 2 & 1 & 3 & 0 & 0 & 0 & 0 & 0 & 0 & 0 & 0 & 0 & 0 & 0 & 0 & 0 & 0 & 0 & 0 & 0 & 0 & 0 & 0 \\
\hline 2 & 1 & 4 & 0 & 0 & 0 & 0 & 0 & 0 & 0 & 0 & 0 & 0 & 0 & 0 & 0 & 0 & 0 & 0 & 0 & 0 & 0 & 0 \\
\hline 2 & 2 & 0 & 0 & 167 & 334 & 501 & 668 & 835 & 1002 & 1022 & 1022 & 1022 & 1022 & 1022 & 1022 & 1022 & 1022 & 1022 & 1022 & 1022 & 1022 & 1022 \\
\hline 2 & 2 & 1 & 0 & 0 & 0 & 0 & 0 & 0 & 0 & 105 & 105 & 105 & 217 & 384 & 451 & 451 & 451 & 451 & 451 & 451 & 451 & 451 \\
\hline 2 & 2 & 2 & 0 & 0 & 0 & 0 & 0 & 0 & 0 & 0 & 0 & 0 & 0 & 0 & 100 & 100 & 100 & 100 & 100 & 100 & 100 & 100 \\
\hline 2 & 2 & 3 & 0 & 0 & 0 & 0 & 0 & 0 & 0 & 42 & 209 & 376 & 431 & 431 & 431 & 431 & 431 & 431 & 431 & 431 & 431 & 431 \\
\hline 2 & 2 & 4 & 0 & 0 & 0 & 0 & 0 & 0 & 0 & 0 & 0 & 0 & 0 & 0 & 0 & 167 & 334 & 501 & 662 & 777 & 891 & 650 \\
\hline
\end{tabular}

\begin{tabular}{|c|c|c|c|c|c|c|c|c|c|c|c|c|c|c|c|c|c|c|c|c|c|c|}
\hline \multicolumn{3}{|c|}{$x_{L m p}^{t}{ }^{*}$} & \multicolumn{20}{|c|}{ Efficient solutions set } \\
\hline$m$ & $p$ & $t$ & 1 & 2 & 3 & 4 & 5 & 6 & 7 & 8 & 9 & 10 & 11 & 12 & 13 & 14 & 15 & 16 & 17 & 18 & 19 & 20 \\
\hline 1 & 1 & 0 & 70 & 70 & 70 & 70 & 70 & 70 & 70 & 70 & 70 & 70 & 70 & 70 & 70 & 70 & 70 & 70 & 70 & 70 & 70 & 70 \\
\hline 1 & 1 & 1 & 80 & 80 & 80 & 80 & 80 & 80 & 80 & 80 & 80 & 80 & 80 & 80 & 80 & 80 & 80 & 80 & 80 & 80 & 80 & 80 \\
\hline 1 & 1 & 2 & 88 & 88 & 88 & 88 & 88 & 88 & 88 & 88 & 88 & 88 & 88 & 88 & 88 & 88 & 88 & 88 & 88 & 88 & 88 & 88 \\
\hline 1 & 1 & 3 & 88 & 88 & 88 & 88 & 88 & 88 & 88 & 88 & 88 & 88 & 88 & 88 & 88 & 88 & 88 & 88 & 88 & 88 & 88 & 88 \\
\hline 1 & 1 & 4 & 115 & 115 & 115 & 115 & 115 & 115 & 115 & 115 & 115 & 115 & 115 & 115 & 115 & 115 & 115 & 115 & 115 & 115 & 115 & 115 \\
\hline 2 & 1 & 0 & 41 & 41 & 41 & 41 & 41 & 41 & 41 & 41 & 41 & 41 & 41 & 41 & 41 & 41 & 41 & 41 & 41 & 41 & 41 & 41 \\
\hline 2 & 1 & 1 & 8 & 8 & 8 & 8 & 8 & 8 & 8 & 8 & 8 & 8 & 8 & 8 & 8 & 8 & 8 & 8 & 8 & 8 & 8 & 8 \\
\hline 2 & 1 & 2 & 0 & 0 & 0 & 0 & 0 & 0 & 0 & 0 & 0 & 0 & 0 & 0 & 0 & 0 & 0 & 0 & 0 & 0 & 0 & 0 \\
\hline 2 & 1 & 3 & 0 & 0 & 0 & 0 & 0 & 0 & 0 & 0 & 0 & 0 & 0 & 0 & 0 & 0 & 0 & 0 & 0 & 0 & 0 & 0 \\
\hline 2 & 1 & 4 & 0 & 0 & 0 & 0 & 0 & 0 & 0 & 0 & 0 & 0 & 0 & 0 & 0 & 0 & 0 & 0 & 0 & 0 & 0 & 0 \\
\hline 1 & 2 & 0 & 55 & 55 & 55 & 55 & 55 & 55 & 55 & 55 & 55 & 55 & 55 & 55 & 55 & 55 & 55 & 55 & 55 & 55 & 55 & 55 \\
\hline 1 & 2 & 1 & 64 & 64 & 64 & 64 & 64 & 64 & 64 & 64 & 64 & 64 & 64 & 64 & 64 & 64 & 64 & 64 & 64 & 64 & 64 & 64 \\
\hline 1 & 2 & 2 & 72 & 72 & 72 & 72 & 72 & 72 & 72 & 72 & 72 & 72 & 72 & 72 & 72 & 72 & 72 & 72 & 72 & 72 & 72 & 72 \\
\hline 1 & 2 & 3 & 69 & 69 & 69 & 69 & 69 & 69 & 69 & 69 & 69 & 69 & 69 & 69 & 69 & 69 & 69 & 69 & 69 & 69 & 69 & 69 \\
\hline 1 & 2 & 4 & 107 & 107 & 107 & 107 & 107 & 107 & 107 & 107 & 107 & 107 & 107 & 107 & 107 & 107 & 107 & 107 & 107 & 107 & 107 & 107 \\
\hline 2 & 2 & 0 & 61 & 61 & 61 & 61 & 61 & 61 & 61 & 61 & 61 & 61 & 61 & 61 & 61 & 61 & 61 & 61 & 61 & 61 & 61 & 61 \\
\hline 2 & 2 & 1 & 9 & 9 & 9 & 9 & 9 & 9 & 9 & 9 & 9 & 9 & 9 & 9 & 9 & 9 & 9 & 9 & 9 & 9 & 9 & 9 \\
\hline 2 & 2 & 2 & 0 & 0 & 0 & 0 & 0 & 0 & 0 & 0 & 0 & 0 & 0 & 0 & 0 & 0 & 0 & 0 & 0 & 0 & 0 & 0 \\
\hline 2 & 2 & 3 & 0 & 0 & 0 & 0 & 0 & 0 & 0 & 0 & 0 & 0 & 0 & 0 & 0 & 0 & 0 & 0 & 0 & 0 & 0 & 0 \\
\hline 2 & 2 & 4 & 0 & 0 & 0 & 0 & 0 & 0 & 0 & 0 & 0 & 0 & 0 & 0 & 0 & 0 & 0 & 0 & 0 & 0 & 0 & 0 \\
\hline
\end{tabular}

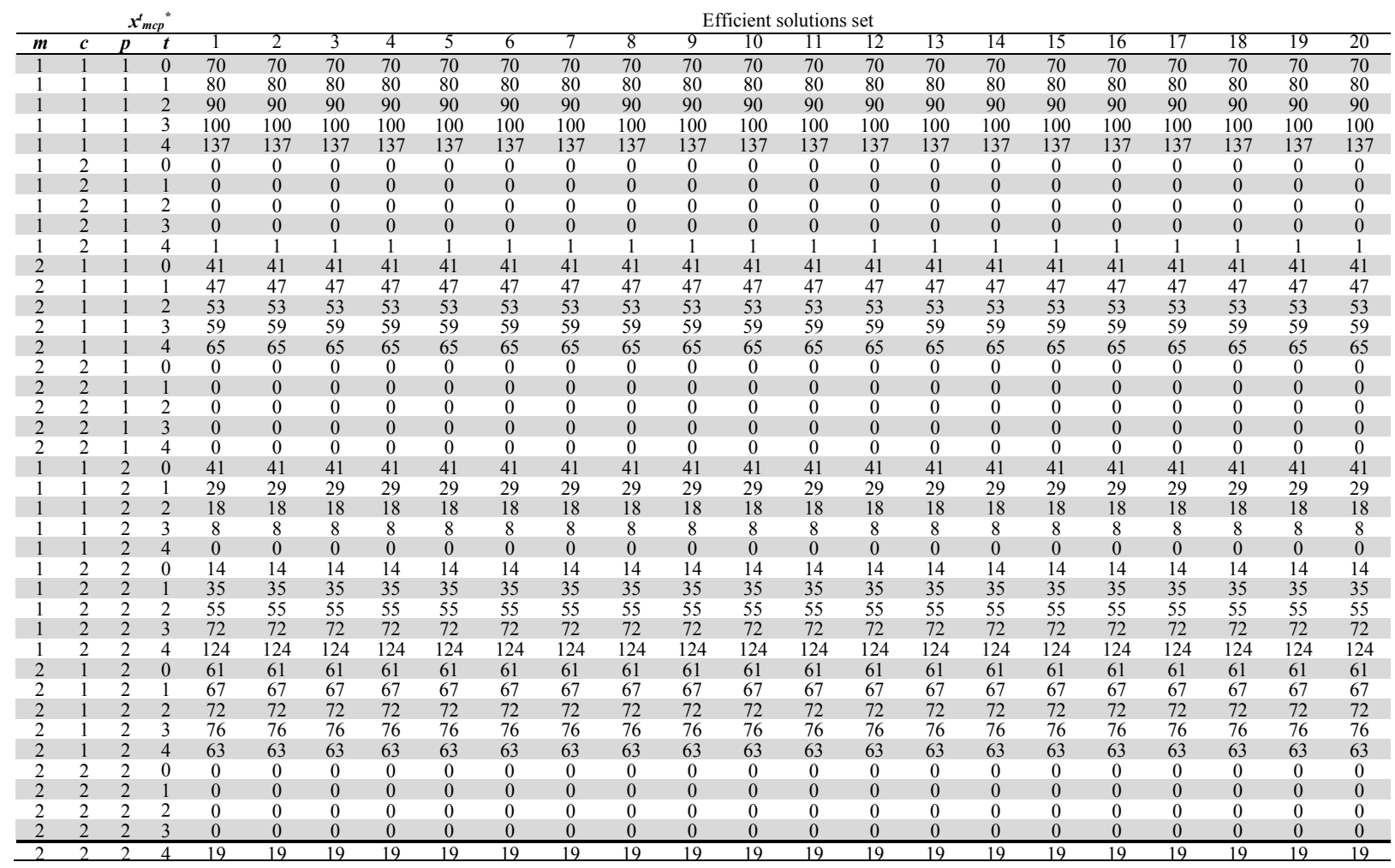




\begin{tabular}{|c|c|c|c|c|c|c|c|c|c|c|c|c|c|c|c|c|c|c|c|c|c|c|c|}
\hline \multicolumn{5}{|c|}{$\boldsymbol{x}_{c f p}^{t}{ }^{*}$} & \multicolumn{19}{|c|}{ Efficient solutions set } \\
\hline$c$ & $\bar{f}$ & $p$ & $t$ & 1 & 2 & 3 & 4 & 5 & 6 & 7 & 8 & 9 & 10 & 11 & 12 & 13 & 14 & 15 & 16 & 17 & 18 & 19 & 20 \\
\hline 1 & 1 & 1 & 0 & 60 & 60 & 60 & 60 & 60 & 60 & 60 & 60 & 60 & 60 & 60 & 60 & 60 & 60 & 60 & 60 & 60 & 60 & 60 & 60 \\
\hline 1 & 1 & 1 & 1 & 60 & 60 & 60 & 60 & 60 & 60 & 60 & 60 & 60 & 60 & 60 & 60 & 60 & 60 & 60 & 60 & 60 & 60 & 60 & 60 \\
\hline 1 & 1 & 1 & 2 & 60 & 60 & 60 & 60 & 60 & 60 & 60 & 60 & 60 & 60 & 60 & 60 & 60 & 60 & 60 & 60 & 60 & 60 & 60 & 60 \\
\hline 1 & 1 & 1 & 3 & 54 & 54 & 54 & 54 & 54 & 54 & 54 & 54 & 54 & 54 & 54 & 54 & 54 & 54 & 54 & 54 & 54 & 54 & 54 & 54 \\
\hline 1 & 1 & 1 & 4 & 18 & 18 & 18 & 18 & 18 & 18 & 18 & 18 & 18 & 18 & 18 & 18 & 18 & 18 & 18 & 18 & 18 & 18 & 18 & 18 \\
\hline 1 & 2 & 1 & 0 & 0 & 0 & 0 & 0 & 0 & 0 & 0 & 0 & 0 & 0 & 0 & 0 & 0 & 0 & 0 & 0 & 0 & 0 & 0 & 0 \\
\hline 1 & 2 & 1 & 1 & 0 & 0 & 0 & 0 & 0 & 0 & 0 & 0 & 0 & 0 & 0 & 0 & 0 & 0 & 0 & 0 & 0 & 0 & 0 & 0 \\
\hline 1 & 2 & 1 & 2 & 0 & 0 & 0 & 0 & 0 & 0 & 0 & 0 & 0 & 0 & 0 & 0 & 0 & 0 & 0 & 0 & 0 & 0 & 0 & 0 \\
\hline 1 & 2 & 1 & 3 & 0 & 0 & 0 & 0 & 0 & 0 & 0 & 0 & 0 & 0 & 0 & 0 & 0 & 0 & 0 & 0 & 0 & 0 & 0 & 0 \\
\hline 1 & 2 & 1 & 4 & 0 & 0 & 0 & 0 & 0 & 0 & 0 & 0 & 0 & 0 & 0 & 0 & 0 & 0 & 0 & 0 & 0 & 0 & 0 & 0 \\
\hline 2 & 1 & 1 & 0 & 0 & 0 & 0 & 0 & 0 & 0 & 0 & 0 & 0 & 0 & 0 & 0 & 0 & 0 & 0 & 0 & 0 & 0 & 0 & 0 \\
\hline 2 & 1 & 1 & 1 & 0 & 0 & 0 & 0 & 0 & 0 & 0 & 0 & 0 & 0 & 0 & 0 & 0 & 0 & 0 & 0 & 0 & 0 & 0 & 0 \\
\hline 2 & 1 & 1 & 2 & 0 & 0 & 0 & 0 & 0 & 0 & 0 & 0 & 0 & 0 & 0 & 0 & 0 & 0 & 0 & 0 & 0 & 0 & 0 & 0 \\
\hline 2 & 1 & 1 & 3 & 0 & 0 & 0 & 0 & 0 & 0 & 0 & 0 & 0 & 0 & 0 & 0 & 0 & 0 & 0 & 0 & 0 & 0 & 0 & 0 \\
\hline 2 & 1 & 1 & 4 & 0 & 0 & 0 & 0 & 0 & 0 & 0 & 0 & 0 & 0 & 0 & 0 & 0 & 0 & 0 & 0 & 0 & 0 & 0 & 0 \\
\hline 2 & 2 & 1 & 0 & 0 & 0 & 0 & 0 & 0 & 0 & 0 & 0 & 0 & 0 & 0 & 0 & 0 & 0 & 0 & 0 & 0 & 0 & 0 & 0 \\
\hline 2 & 2 & 1 & 1 & 0 & 0 & 0 & 0 & 0 & 0 & 0 & 0 & 0 & 0 & 0 & 0 & 0 & 0 & 0 & 0 & 0 & 0 & 0 & 0 \\
\hline 2 & 2 & 1 & 2 & 0 & 0 & 0 & 0 & 0 & 0 & 0 & 0 & 0 & 0 & 0 & 0 & 0 & 0 & 0 & 0 & 0 & 0 & 0 & 0 \\
\hline 2 & 2 & 1 & 3 & 6 & 6 & 6 & 6 & 6 & 6 & 6 & 6 & 6 & 6 & 6 & 6 & 6 & 6 & 6 & 6 & 6 & 6 & 6 & 6 \\
\hline 2 & 2 & 1 & 4 & 42 & 42 & 42 & 42 & 42 & 42 & 42 & 42 & 42 & 42 & 42 & 42 & 42 & 42 & 42 & 42 & 42 & 42 & 42 & 42 \\
\hline 1 & 1 & 2 & 0 & 46 & 46 & 46 & 46 & 46 & 46 & 46 & 46 & 46 & 46 & 46 & 46 & 46 & 46 & 46 & 46 & 46 & 46 & 46 & 46 \\
\hline 1 & 1 & 2 & 1 & 25 & 25 & 25 & 25 & 25 & 25 & 25 & 25 & 25 & 25 & 25 & 25 & 25 & 25 & 25 & 25 & 25 & 25 & 25 & 25 \\
\hline 1 & 1 & 2 & 2 & 5 & 5 & 5 & 5 & 5 & 5 & 5 & 5 & 5 & 5 & 5 & 5 & 5 & 5 & 5 & 5 & 5 & 5 & 5 & 5 \\
\hline 1 & 1 & 2 & 3 & 0 & 0 & 0 & 0 & 0 & 0 & 0 & 0 & 0 & 0 & 0 & 0 & 0 & 0 & 0 & 0 & 0 & 0 & 0 & 0 \\
\hline 1 & 1 & 2 & 4 & 0 & 0 & 0 & 0 & 0 & 0 & 0 & 0 & 0 & 0 & 0 & 0 & 0 & 0 & 0 & 0 & 0 & 0 & 0 & 0 \\
\hline 1 & 2 & 2 & 0 & 0 & 0 & 0 & 0 & 0 & 0 & 0 & 0 & 0 & 0 & 0 & 0 & 0 & 0 & 0 & 0 & 0 & 0 & 0 & 0 \\
\hline 1 & 2 & 2 & 1 & 0 & 0 & 0 & 0 & 0 & 0 & 0 & 0 & 0 & 0 & 0 & 0 & 0 & 0 & 0 & 0 & 0 & 0 & 0 & 0 \\
\hline 1 & 2 & 2 & 2 & 0 & 0 & 0 & 0 & 0 & 0 & 0 & 0 & 0 & 0 & 0 & 0 & 0 & 0 & 0 & 0 & 0 & 0 & 0 & 0 \\
\hline 1 & 2 & 2 & 3 & 0 & 0 & 0 & 0 & 0 & 0 & 0 & 0 & 0 & 0 & 0 & 0 & 0 & 0 & 0 & 0 & 0 & 0 & 0 & 0 \\
\hline 1 & 2 & 2 & 4 & 0 & 0 & 0 & 0 & 0 & 0 & 0 & 0 & 0 & 0 & 0 & 0 & 0 & 0 & 0 & 0 & 0 & 0 & 0 & 0 \\
\hline 2 & 1 & 2 & 0 & 0 & 0 & 0 & 0 & 0 & 0 & 0 & 0 & 0 & 0 & 0 & 0 & 0 & 0 & 0 & 0 & 0 & 0 & 0 & 0 \\
\hline 2 & 1 & 2 & 1 & 0 & 0 & 0 & 0 & 0 & 0 & 0 & 0 & 0 & 0 & 0 & 0 & 0 & 0 & 0 & 0 & 0 & 0 & 0 & 0 \\
\hline 2 & 1 & 2 & 2 & 0 & 0 & 0 & 0 & 0 & 0 & 0 & 0 & 0 & 0 & 0 & 0 & 0 & 0 & 0 & 0 & 0 & 0 & 0 & 0 \\
\hline 2 & 1 & 2 & 3 & 0 & 0 & 0 & 0 & 0 & 0 & 0 & 0 & 0 & 0 & 0 & 0 & 0 & 0 & 0 & 0 & 0 & 0 & 0 & 0 \\
\hline 2 & 1 & 2 & 4 & 0 & 0 & 0 & 0 & 0 & 0 & 0 & 0 & 0 & 0 & 0 & 0 & 0 & 0 & 0 & 0 & 0 & 0 & 0 & 0 \\
\hline 2 & 2 & 2 & 0 & 14 & 14 & 14 & 14 & 14 & 14 & 14 & 14 & 14 & 14 & 14 & 14 & 14 & 14 & 14 & 14 & 14 & 14 & 14 & 14 \\
\hline 2 & 2 & 2 & 1 & 35 & 35 & 35 & 35 & 35 & 35 & 35 & 35 & 35 & 35 & 35 & 35 & 35 & 35 & 35 & 35 & 35 & 35 & 35 & 35 \\
\hline 2 & 2 & 2 & 2 & 55 & 55 & 55 & 55 & 55 & 55 & 55 & 55 & 55 & 55 & 55 & 55 & 55 & 55 & 55 & 55 & 55 & 55 & 55 & 55 \\
\hline 2 & 2 & 2 & 3 & 60 & 60 & 60 & 60 & 60 & 60 & 60 & 60 & 60 & 60 & 60 & 60 & 60 & 60 & 60 & 60 & 60 & 60 & 60 & 60 \\
\hline 2 & 2 & 2 & 4 & 60 & 60 & 60 & 60 & 60 & 60 & 60 & 60 & 60 & 60 & 60 & 60 & 60 & 60 & 60 & 60 & 60 & 60 & 60 & 60 \\
\hline
\end{tabular}

$\boldsymbol{x}_{\text {cuq }}{ }^{*}$

Efficient solutions set

\begin{tabular}{|c|c|c|c|c|c|c|c|c|c|c|c|c|c|c|c|c|c|c|c|c|c|c|c|}
\hline$c$ & $\boldsymbol{u}$ & $q$ & $t$ & 1 & 2 & 3 & 4 & 5 & 6 & 7 & 8 & 9 & 10 & 11 & 12 & 13 & 14 & 15 & 16 & 17 & 18 & 19 & 20 \\
\hline 1 & 1 & 1 & 0 & 274 & 274 & 274 & 274 & 274 & 274 & 274 & 274 & 274 & 274 & 274 & 274 & 274 & 274 & 274 & 274 & 274 & 274 & 274 & 274 \\
\hline 1 & 1 & 1 & 1 & 368 & 368 & 368 & 368 & 368 & 368 & 368 & 368 & 368 & 368 & 368 & 368 & 368 & 368 & 368 & 368 & 368 & 368 & 368 & 368 \\
\hline 1 & 1 & 1 & 2 & 441 & 441 & 441 & 441 & 441 & 441 & 441 & 441 & 441 & 441 & 441 & 441 & 441 & 441 & 441 & 441 & 441 & 441 & 441 & 441 \\
\hline 1 & 1 & 1 & 3 & 501 & 501 & 501 & 501 & 501 & 501 & 501 & 501 & 501 & 501 & 501 & 501 & 501 & 501 & 501 & 501 & 501 & 501 & 501 & 501 \\
\hline 1 & 1 & 1 & 4 & 538 & 538 & 538 & 538 & 538 & 538 & 538 & 538 & 538 & 538 & 538 & 538 & 538 & 538 & 538 & 538 & 538 & 538 & 538 & 538 \\
\hline 1 & 2 & 1 & 0 & 0 & 0 & 0 & 0 & 0 & 0 & 0 & 0 & 0 & 0 & 0 & 0 & 0 & 0 & 0 & 0 & 0 & 0 & 0 & 0 \\
\hline 1 & 2 & 1 & 1 & 0 & 0 & 0 & 0 & 0 & 0 & 0 & 0 & 0 & 0 & 0 & 0 & 0 & 0 & 0 & 0 & 0 & 0 & 0 & 0 \\
\hline 1 & 2 & 1 & 2 & 20 & 20 & 20 & 20 & 20 & 20 & 20 & 20 & 20 & 20 & 20 & 20 & 20 & 20 & 20 & 20 & 20 & 20 & 20 & 20 \\
\hline 1 & 2 & 1 & 3 & 46 & 46 & 46 & 46 & 46 & 46 & 46 & 46 & 46 & 46 & 46 & 46 & 46 & 46 & 46 & 46 & 46 & 46 & 46 & 46 \\
\hline 1 & 2 & 1 & 4 & 282 & 282 & 282 & 282 & 282 & 282 & 282 & 282 & 282 & 282 & 282 & 282 & 282 & 282 & 282 & 282 & 282 & 282 & 282 & 282 \\
\hline 2 & 1 & 1 & 0 & 0 & 0 & 0 & 0 & 0 & 0 & 0 & 0 & 0 & 0 & 0 & 0 & 0 & 0 & 0 & 0 & 0 & 0 & 0 & 0 \\
\hline 2 & 1 & 1 & 1 & 0 & 0 & 0 & 0 & 0 & 0 & 0 & 0 & 0 & 0 & 0 & 0 & 0 & 0 & 0 & 0 & 0 & 0 & 0 & 0 \\
\hline 2 & 1 & 1 & 2 & 0 & 0 & 0 & 0 & 0 & 0 & 0 & 0 & 0 & 0 & 0 & 0 & 0 & 0 & 0 & 0 & 0 & 0 & 0 & 0 \\
\hline 2 & 1 & 1 & 3 & 0 & 0 & 0 & 0 & 0 & 0 & 0 & 0 & 0 & 0 & 0 & 0 & 0 & 0 & 0 & 0 & 0 & 0 & 0 & 0 \\
\hline 2 & 1 & 1 & 4 & 0 & 0 & 0 & 0 & 0 & 0 & 0 & 0 & 0 & 0 & 0 & 0 & 0 & 0 & 0 & 0 & 0 & 0 & 0 & 0 \\
\hline 2 & 2 & 1 & 0 & 0 & 0 & 0 & 0 & 0 & 0 & 0 & 0 & 0 & 0 & 0 & 0 & 0 & 0 & 0 & 0 & 0 & 0 & 0 & 0 \\
\hline 2 & 2 & 1 & 1 & 0 & 0 & 0 & 0 & 0 & 0 & 0 & 0 & 0 & 0 & 0 & 0 & 0 & 0 & 0 & 0 & 0 & 0 & 0 & 0 \\
\hline 2 & 2 & 1 & 2 & 0 & 0 & 0 & 0 & 0 & 0 & 0 & 0 & 0 & 0 & 0 & 0 & 0 & 0 & 0 & 0 & 0 & 0 & 0 & 0 \\
\hline 2 & 2 & 1 & 3 & 0 & 0 & 0 & 0 & 0 & 0 & 0 & 0 & 0 & 0 & 0 & 0 & 0 & 0 & 0 & 0 & 0 & 0 & 0 & 0 \\
\hline 2 & 2 & 1 & 4 & 0 & 0 & 0 & 0 & 0 & 0 & 0 & 0 & 0 & 0 & 0 & 0 & 0 & 0 & 0 & 0 & 0 & 0 & 0 & 0 \\
\hline 1 & 1 & 2 & 0 & 331 & 331 & 331 & 331 & 331 & 331 & 331 & 331 & 331 & 331 & 331 & 331 & 331 & 331 & 331 & 331 & 331 & 331 & 331 & 331 \\
\hline 1 & 1 & 2 & 1 & 422 & 422 & 422 & 422 & 422 & 422 & 422 & 422 & 422 & 422 & 422 & 422 & 422 & 422 & 422 & 422 & 422 & 422 & 422 & 422 \\
\hline 1 & 1 & 2 & 2 & 459 & 459 & 459 & 459 & 459 & 459 & 459 & 459 & 459 & 459 & 459 & 459 & 459 & 459 & 459 & 459 & 459 & 459 & 459 & 459 \\
\hline 1 & 1 & 2 & 3 & 410 & 410 & 410 & 410 & 410 & 410 & 410 & 410 & 410 & 410 & 410 & 410 & 410 & 410 & 410 & 410 & 410 & 410 & 410 & 410 \\
\hline 1 & 1 & 2 & 4 & 100 & 100 & 100 & 100 & 100 & 100 & 100 & 100 & 100 & 100 & 100 & 100 & 100 & 100 & 100 & 100 & 100 & 100 & 100 & 100 \\
\hline 1 & 2 & 2 & 0 & 0 & 0 & 0 & 0 & 0 & 0 & 0 & 0 & 0 & 0 & 0 & 0 & 0 & 0 & 0 & 0 & 0 & 0 & 0 & 0 \\
\hline 1 & 2 & 2 & 1 & 0 & 0 & 0 & 0 & 0 & 0 & 0 & 0 & 0 & 0 & 0 & 0 & 0 & 0 & 0 & 0 & 0 & 0 & 0 & 0 \\
\hline 1 & 2 & 2 & 2 & 49 & 49 & 49 & 49 & 49 & 49 & 49 & 49 & 49 & 49 & 49 & 49 & 49 & 49 & 49 & 49 & 49 & 49 & 49 & 49 \\
\hline 1 & 2 & 2 & 3 & 114 & 114 & 114 & 114 & 114 & 114 & 114 & 114 & 114 & 114 & 114 & 114 & 114 & 114 & 114 & 114 & 114 & 114 & 114 & 114 \\
\hline 1 & 2 & 2 & 4 & 398 & 398 & 398 & 398 & 398 & 398 & 398 & 398 & 398 & 398 & 398 & 398 & 398 & 398 & 398 & 398 & 398 & 398 & 398 & 398 \\
\hline 2 & 1 & 2 & 0 & 0 & 0 & 0 & 0 & 0 & 0 & 0 & 0 & 0 & 0 & 0 & 0 & 0 & 0 & 0 & 0 & 0 & 0 & 0 & 0 \\
\hline 2 & 1 & 2 & 1 & 0 & 0 & 0 & 0 & 0 & 0 & 0 & 0 & 0 & 0 & 0 & 0 & 0 & 0 & 0 & 0 & 0 & 0 & 0 & 0 \\
\hline 2 & 1 & 2 & 2 & 0 & 0 & 0 & 0 & 0 & 0 & 0 & 0 & 0 & 0 & 0 & 0 & 0 & 0 & 0 & 0 & 0 & 0 & 0 & 0 \\
\hline 2 & 1 & 2 & 3 & 55 & 55 & 55 & 55 & 55 & 55 & 55 & 55 & 55 & 55 & 55 & 55 & 55 & 55 & 55 & 55 & 55 & 55 & 55 & 55 \\
\hline 2 & 1 & 2 & 4 & 371 & 371 & 371 & 371 & 371 & 371 & 371 & 371 & 371 & 371 & 371 & 371 & 371 & 371 & 371 & 371 & 371 & 371 & 371 & 371 \\
\hline 2 & 2 & 2 & 0 & 0 & 0 & 0 & 0 & 0 & 0 & 0 & 0 & 0 & 0 & 0 & 0 & 0 & 0 & 0 & 0 & 0 & 0 & 0 & 0 \\
\hline 2 & 2 & 2 & 1 & 0 & 0 & 0 & 0 & 0 & 0 & 0 & 0 & 0 & 0 & 0 & 0 & 0 & 0 & 0 & 0 & 0 & 0 & 0 & 0 \\
\hline 2 & 2 & 2 & 2 & 0 & 0 & 0 & 0 & 0 & 0 & 0 & 0 & 0 & 0 & 0 & 0 & 0 & 0 & 0 & 0 & 0 & 0 & 0 & 0 \\
\hline 2 & 2 & 2 & 3 & 0 & 0 & 0 & 0 & 0 & 0 & 0 & 0 & 0 & 0 & 0 & 0 & 0 & 0 & 0 & 0 & 0 & 0 & 0 & 0 \\
\hline 2 & 2 & 2 & 4 & 0 & 0 & 0 & 0 & 0 & 0 & 0 & 0 & 0 & 0 & 0 & 0 & 0 & 0 & 0 & 0 & 0 & 0 & 0 & 0 \\
\hline
\end{tabular}


$\boldsymbol{x}_{\text {ump }}^{t}{ }^{*} \quad$ Efficient solutions set

\begin{tabular}{|c|c|c|c|c|c|c|c|c|c|c|c|c|c|c|c|c|c|c|c|c|c|c|c|}
\hline$u$ & $m$ & $p$ & $t$ & 1 & 2 & 3 & 4 & 5 & 6 & 7 & 8 & 9 & 10 & 11 & 12 & 13 & 14 & 15 & 16 & 17 & 18 & 19 & 20 \\
\hline 1 & 1 & 1 & 0 & 0 & 0 & 0 & 0 & 0 & 0 & 0 & 0 & 0 & 0 & 0 & 0 & 0 & 0 & 0 & 0 & 0 & 0 & 0 & 0 \\
\hline 1 & 1 & 1 & 1 & 0 & 0 & 0 & 0 & 0 & 0 & 0 & 0 & 0 & 0 & 0 & 0 & 0 & 0 & 0 & 0 & 0 & 0 & 0 & 0 \\
\hline 1 & 1 & 1 & 2 & 2 & 2 & 2 & 2 & 2 & 2 & 2 & 2 & 2 & 2 & 2 & 2 & 2 & 2 & 2 & 2 & 2 & 2 & 2 & 2 \\
\hline 1 & 1 & 1 & 3 & 12 & 12 & 12 & 12 & 12 & 12 & 12 & 12 & 12 & 12 & 12 & 12 & 12 & 12 & 12 & 12 & 12 & 12 & 12 & 12 \\
\hline 1 & 1 & 1 & 4 & 22 & 22 & 22 & 22 & 22 & 22 & 22 & 22 & 22 & 22 & 22 & 22 & 22 & 22 & 22 & 22 & 22 & 22 & 22 & 22 \\
\hline 2 & 1 & 1 & 0 & 0 & 0 & 0 & 0 & 0 & 0 & 0 & 0 & 0 & 0 & 0 & 0 & 0 & 0 & 0 & 0 & 0 & 0 & 0 & 0 \\
\hline 2 & 1 & 1 & 1 & 0 & 0 & 0 & 0 & 0 & 0 & 0 & 0 & 0 & 0 & 0 & 0 & 0 & 0 & 0 & 0 & 0 & 0 & 0 & 0 \\
\hline 2 & 1 & 1 & 2 & 0 & 0 & 0 & 0 & 0 & 0 & 0 & 0 & 0 & 0 & 0 & 0 & 0 & 0 & 0 & 0 & 0 & 0 & 0 & 0 \\
\hline 2 & 1 & 1 & 3 & 0 & 0 & 0 & 0 & 0 & 0 & 0 & 0 & 0 & 0 & 0 & 0 & 0 & 0 & 0 & 0 & 0 & 0 & 0 & 0 \\
\hline 2 & 1 & 1 & 4 & 0 & 0 & 0 & 0 & 0 & 0 & 0 & 0 & 0 & 0 & 0 & 0 & 0 & 0 & 0 & 0 & 0 & 0 & 0 & 0 \\
\hline 1 & 2 & 1 & 0 & 0 & 0 & 0 & 0 & 0 & 0 & 0 & 0 & 0 & 0 & 0 & 0 & 0 & 0 & 0 & 0 & 0 & 0 & 0 & 0 \\
\hline 1 & 2 & 1 & 1 & 39 & 39 & 39 & 39 & 39 & 39 & 39 & 39 & 39 & 39 & 39 & 39 & 39 & 39 & 39 & 39 & 39 & 39 & 39 & 39 \\
\hline 1 & 2 & 1 & 2 & 53 & 53 & 53 & 53 & 53 & 53 & 53 & 53 & 53 & 53 & 53 & 53 & 53 & 53 & 53 & 53 & 53 & 53 & 53 & 53 \\
\hline 1 & 2 & 1 & 3 & 59 & 59 & 59 & 59 & 59 & 59 & 59 & 59 & 59 & 59 & 59 & 59 & 59 & 59 & 59 & 59 & 59 & 59 & 59 & 59 \\
\hline 1 & 2 & 1 & 4 & 65 & 65 & 65 & 65 & 65 & 65 & 65 & 65 & 65 & 65 & 65 & 65 & 65 & 65 & 65 & 65 & 65 & 65 & 65 & 65 \\
\hline 2 & 2 & 1 & 0 & 0 & 0 & 0 & 0 & 0 & 0 & 0 & 0 & 0 & 0 & 0 & 0 & 0 & 0 & 0 & 0 & 0 & 0 & 0 & 0 \\
\hline 2 & 2 & 1 & 1 & 0 & 0 & 0 & 0 & 0 & 0 & 0 & 0 & 0 & 0 & 0 & 0 & 0 & 0 & 0 & 0 & 0 & 0 & 0 & 0 \\
\hline 2 & 2 & 1 & 2 & 0 & 0 & 0 & 0 & 0 & 0 & 0 & 0 & 0 & 0 & 0 & 0 & 0 & 0 & 0 & 0 & 0 & 0 & 0 & 0 \\
\hline 2 & 2 & 1 & 3 & 0 & 0 & 0 & 0 & 0 & 0 & 0 & 0 & 0 & 0 & 0 & 0 & 0 & 0 & 0 & 0 & 0 & 0 & 0 & 0 \\
\hline 2 & 2 & 1 & 4 & 0 & 0 & 0 & 0 & 0 & 0 & 0 & 0 & 0 & 0 & 0 & 0 & 0 & 0 & 0 & 0 & 0 & 0 & 0 & 0 \\
\hline 1 & 1 & 2 & 0 & 0 & 0 & 0 & 0 & 0 & 0 & 0 & 0 & 0 & 0 & 0 & 0 & 0 & 0 & 0 & 0 & 0 & 0 & 0 & 0 \\
\hline 1 & 1 & 2 & 1 & 0 & 0 & 0 & 0 & 0 & 0 & 0 & 0 & 0 & 0 & 0 & 0 & 0 & 0 & 0 & 0 & 0 & 0 & 0 & 0 \\
\hline 1 & 1 & 2 & 2 & 1 & 1 & 1 & 1 & 1 & 1 & 1 & 1 & 1 & 1 & 1 & 1 & 1 & 1 & 1 & 1 & 1 & 1 & 1 & 1 \\
\hline 1 & 1 & 2 & 3 & 2 & 2 & 2 & 2 & 2 & 2 & 2 & 2 & 2 & 2 & 2 & 2 & 2 & 2 & 2 & 2 & 2 & 2 & 2 & 2 \\
\hline 1 & 1 & 2 & 4 & 0 & 0 & 0 & 0 & 0 & 0 & 0 & 0 & 0 & 0 & 0 & 0 & 0 & 0 & 0 & 0 & 0 & 0 & 0 & 0 \\
\hline 2 & 1 & 2 & 0 & 0 & 0 & 0 & 0 & 0 & 0 & 0 & 0 & 0 & 0 & 0 & 0 & 0 & 0 & 0 & 0 & 0 & 0 & 0 & 0 \\
\hline 2 & 1 & 2 & 1 & 0 & 0 & 0 & 0 & 0 & 0 & 0 & 0 & 0 & 0 & 0 & 0 & 0 & 0 & 0 & 0 & 0 & 0 & 0 & 0 \\
\hline 2 & 1 & 2 & 2 & 0 & 0 & 0 & 0 & 0 & 0 & 0 & 0 & 0 & 0 & 0 & 0 & 0 & 0 & 0 & 0 & 0 & 0 & 0 & 0 \\
\hline 2 & 1 & 2 & 3 & 10 & 10 & 10 & 10 & 10 & 10 & 10 & 10 & 10 & 10 & 10 & 10 & 10 & 10 & 10 & 10 & 10 & 10 & 10 & 10 \\
\hline 2 & 1 & 2 & 4 & 17 & 17 & 17 & 17 & 17 & 17 & 17 & 17 & 17 & 17 & 17 & 17 & 17 & 17 & 17 & 17 & 17 & 17 & 17 & 17 \\
\hline 1 & 2 & 2 & 0 & 0 & 0 & 0 & 0 & 0 & 0 & 0 & 0 & 0 & 0 & 0 & 0 & 0 & 0 & 0 & 0 & 0 & 0 & 0 & 0 \\
\hline 1 & 2 & 2 & 1 & 58 & 58 & 58 & 58 & 58 & 58 & 58 & 58 & 58 & 58 & 58 & 58 & 58 & 58 & 58 & 58 & 58 & 58 & 58 & 58 \\
\hline 1 & 2 & 2 & 2 & 72 & 72 & 72 & 72 & 72 & 72 & 72 & 72 & 72 & 72 & 72 & 72 & 72 & 72 & 72 & 72 & 72 & 72 & 72 & 72 \\
\hline 1 & 2 & 2 & 3 & 76 & 76 & 76 & 76 & 76 & 76 & 76 & 76 & 76 & 76 & 76 & 76 & 76 & 76 & 76 & 76 & 76 & 76 & 76 & 76 \\
\hline 1 & 2 & 2 & 4 & 76 & 76 & 76 & 76 & 76 & 76 & 76 & 76 & 76 & 76 & 76 & 76 & 76 & 76 & 76 & 76 & 76 & 76 & 76 & 76 \\
\hline 2 & 2 & 2 & 0 & 0 & 0 & 0 & 0 & 0 & 0 & 0 & 0 & 0 & 0 & 0 & 0 & 0 & 0 & 0 & 0 & 0 & 0 & 0 & 0 \\
\hline 2 & 2 & 2 & 1 & 0 & 0 & 0 & 0 & 0 & 0 & 0 & 0 & 0 & 0 & 0 & 0 & 0 & 0 & 0 & 0 & 0 & 0 & 0 & 0 \\
\hline 2 & 2 & 2 & 2 & 0 & 0 & 0 & 0 & 0 & 0 & 0 & 0 & 0 & 0 & 0 & 0 & 0 & 0 & 0 & 0 & 0 & 0 & 0 & 0 \\
\hline 2 & 2 & 2 & 3 & 0 & 0 & 0 & 0 & 0 & 0 & 0 & 0 & 0 & 0 & 0 & 0 & 0 & 0 & 0 & 0 & 0 & 0 & 0 & 0 \\
\hline 2 & 2 & 2 & 4 & 6 & 6 & 6 & 6 & 6 & 6 & 6 & 6 & 6 & 6 & 6 & 6 & 6 & 6 & 6 & 6 & 6 & 6 & 6 & 6 \\
\hline
\end{tabular}

\begin{tabular}{|c|c|c|c|c|c|c|c|c|c|c|c|c|c|c|c|c|c|c|c|c|c|c|}
\hline \multicolumn{3}{|c|}{$x_{c R q}^{t}{ }^{*}$} & \multicolumn{20}{|c|}{ Efficient solutions set } \\
\hline$c$ & $q$ & $t$ & 1 & 2 & 3 & 4 & 5 & 6 & 7 & 8 & 9 & 10 & 11 & 12 & 13 & 14 & 15 & 16 & 17 & 18 & 19 & 20 \\
\hline 1 & 1 & 0 & 42 & 42 & 42 & 42 & 42 & 42 & 42 & 42 & 42 & 42 & 42 & 42 & 42 & 42 & 42 & 42 & 42 & 42 & 42 & 42 \\
\hline 1 & 1 & 1 & 42 & 42 & 42 & 42 & 42 & 42 & 42 & 42 & 42 & 42 & 42 & 42 & 42 & 42 & 42 & 42 & 42 & 42 & 42 & 42 \\
\hline 1 & 1 & 2 & 42 & 42 & 42 & 42 & 42 & 42 & 42 & 42 & 42 & 42 & 42 & 42 & 42 & 42 & 42 & 42 & 42 & 42 & 42 & 42 \\
\hline 1 & 1 & 3 & 42 & 42 & 42 & 42 & 42 & 42 & 42 & 42 & 42 & 42 & 42 & 42 & 42 & 42 & 42 & 42 & 42 & 42 & 42 & 42 \\
\hline 1 & 1 & 4 & 42 & 42 & 42 & 42 & 42 & 42 & 42 & 42 & 42 & 42 & 42 & 42 & 42 & 42 & 42 & 42 & 42 & 42 & 42 & 42 \\
\hline 2 & 1 & 0 & 0 & 0 & 0 & 0 & 0 & 0 & 0 & 0 & 0 & 0 & 0 & 0 & 0 & 0 & 0 & 0 & 0 & 0 & 0 & 0 \\
\hline 2 & 1 & 1 & 0 & 0 & 0 & 0 & 0 & 0 & 0 & 0 & 0 & 0 & 0 & 0 & 0 & 0 & 0 & 0 & 0 & 0 & 0 & 0 \\
\hline 2 & 1 & 2 & 0 & 0 & 0 & 0 & 0 & 0 & 0 & 0 & 0 & 0 & 0 & 0 & 0 & 0 & 0 & 0 & 0 & 0 & 0 & 0 \\
\hline 2 & 1 & 3 & 0 & 0 & 0 & 0 & 0 & 0 & 0 & 0 & 0 & 0 & 0 & 0 & 0 & 0 & 0 & 0 & 0 & 0 & 0 & 0 \\
\hline 2 & 1 & 4 & 0 & 0 & 0 & 0 & 0 & 0 & 0 & 0 & 0 & 0 & 0 & 0 & 0 & 0 & 0 & 0 & 0 & 0 & 0 & 0 \\
\hline 1 & 2 & 0 & 0 & 0 & 0 & 0 & 0 & 0 & 0 & 0 & 0 & 0 & 0 & 0 & 0 & 0 & 0 & 0 & 0 & 0 & 0 & 0 \\
\hline 1 & 2 & 1 & 0 & 0 & 0 & 0 & 0 & 0 & 0 & 0 & 0 & 0 & 0 & 0 & 0 & 0 & 0 & 0 & 0 & 0 & 0 & 0 \\
\hline 1 & 2 & 2 & 0 & 0 & 0 & 0 & 0 & 0 & 0 & 0 & 0 & 0 & 0 & 0 & 0 & 0 & 0 & 0 & 0 & 0 & 0 & 0 \\
\hline 1 & 2 & 3 & 0 & 0 & 0 & 0 & 0 & 0 & 0 & 0 & 0 & 0 & 0 & 0 & 0 & 0 & 0 & 0 & 0 & 0 & 0 & 0 \\
\hline 1 & 2 & 4 & 0 & 0 & 0 & 0 & 0 & 0 & 0 & 0 & 0 & 0 & 0 & 0 & 0 & 0 & 0 & 0 & 0 & 0 & 0 & 0 \\
\hline 2 & 2 & 0 & 0 & 0 & 0 & 0 & 0 & 0 & 0 & 0 & 0 & 0 & 0 & 0 & 0 & 0 & 0 & 0 & 0 & 0 & 0 & 0 \\
\hline 2 & 2 & 1 & 0 & 0 & 0 & 0 & 0 & 0 & 0 & 0 & 0 & 0 & 0 & 0 & 0 & 0 & 0 & 0 & 0 & 0 & 0 & 0 \\
\hline 2 & 2 & 2 & 0 & 0 & 0 & 0 & 0 & 0 & 0 & 0 & 0 & 0 & 0 & 0 & 0 & 0 & 0 & 0 & 0 & 0 & 0 & 0 \\
\hline 2 & 2 & 3 & 0 & 0 & 0 & 0 & 0 & 0 & 0 & 0 & 0 & 0 & 0 & 0 & 0 & 0 & 0 & 0 & 0 & 0 & 0 & 0 \\
\hline 2 & 2 & 4 & 0 & 0 & 0 & 0 & 0 & 0 & 0 & 0 & 0 & 0 & 0 & 0 & 0 & 0 & 0 & 0 & 0 & 0 & 0 & 0 \\
\hline
\end{tabular}

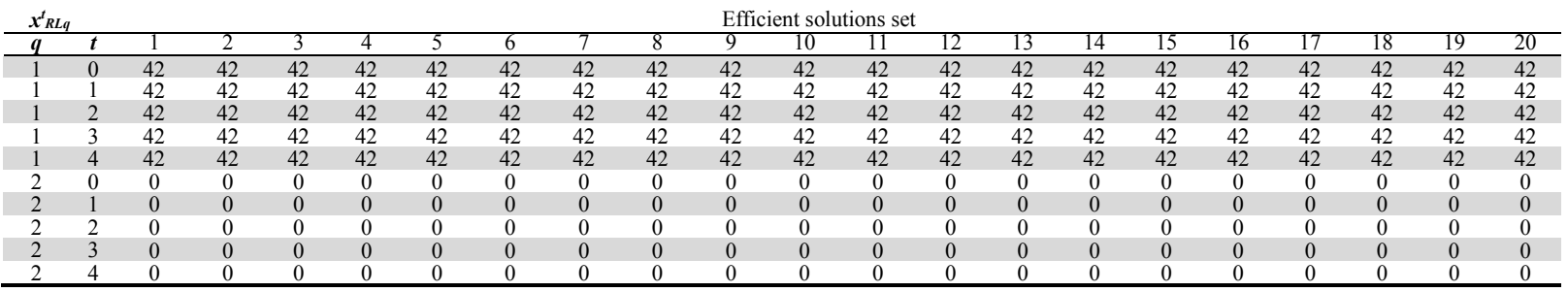

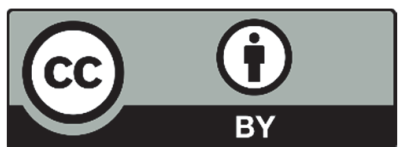

(C) 2018 by the authors; licensee Growing Science, Canada. This is an open access article distributed under the terms and conditions of the Creative Commons Attribution (CC-BY) license (http://creativecommons.org/licenses/by/4.0/). 